\title{
Norcantharidin enhances TIMP-2 anti-vasculogenic mimicry activity for human gallbladder cancers through downregulating MMP-2 and MT1-MMP
}

\author{
WEI ZHU ${ }^{1,2^{*}}$, WEI SUN ${ }^{3 *}$, JING-TAO ZHANG ${ }^{1}$, ZHONG-YAN LIU ${ }^{1}$, XIN-PING LI ${ }^{1}$ and YUE-ZU FAN ${ }^{1}$ \\ ${ }^{1}$ Department of Surgery, Tongji Hospital, Tongji University School of Medicine, Shanghai 200065; Postgraduate \\ on-the-job in 2011 Grade, Tongji University School of Medicine; ${ }^{2}$ Department of Surgery, Dahua Hospital, \\ Shanghai 200237; ${ }^{3}$ Department of Surgery, Shanghai Tenth People's Hospital, Tongji University \\ School of Medicine, Shanghai 200072, P.R. China
}

Received September 12, 2014; Accepted October 24, 2014

DOI: $10.3892 /$ ijo.2014.2753

\begin{abstract}
Vasculogenic mimicry (VM) is a tumor microcirculation pattern in highly aggressive gallbladder cancers (GBCs). We recently reported the anti-VM activity of norcantharidin (NCTD) in highly aggressive GBC-SD cells and xenografts. In this study, we further investigated that NCTD enhanced tissue inhibitor of matrix metalloproteinase-2 (TIMP-2) anti-VM activity for GBCs and the underlying mechanisms. In vivo and in vitro experiments were performed to determine the effects of NCTD in combination with TIMP-2 on tumor growth, host survival, VM formation, hemodynamic of GBC-SD xenografts, and VM-like networks and malignant phenotypes of GBC-SD cells. Expression of matrix metalloproteinase (MMP)-2 and membrane type 1-MMP (MT1-MMP) among human GBCs,
\end{abstract}

Correspondence to: Professor Yue-Zu Fan, Department of Surgery, Tongji Hospital, Tongji University School of Medicine, No. 389 Xincun Road, Shanghai 200065, P.R. China

E-mail: fanyuezu@hotmail.com

*Contributed equally

Abbreviations: GBC, gallbladder cancer; VM, vasculogenic mimicry; NCTD, norcantharidin; MMP, matrix metalloproteinase; MT1-MMP, membrane type 1-MMP; TIMP-2, tissue inhibitor of matrix metalloproteinase-2; 3-D culture, three-dimensional culture; ECM, extracellular matrix; PI3-K, phosphoinositide 3-kinase; Ln-5, laminin-5; EphA2, ephrin type-A receptor 2; FAK, focal adhesion kinase; H\&E, hematoxylin and eosin; PAS, periodic acid-Schiff; IHC, immunohistochemistry; SABC, streptavidin-biotin complex method; DAB, 3,3'-diaminobenzidine; PBS, phosphate buffer solution; TEM, transmission electron microscopy; MTT, tetrazolium-based colorimetric method; FCM, flow cytometry; RT-PCR, reverse transcriptionpolymerase chain reaction

Key words: gallbladder neoplasm, norcantharidin, vasculogenic mimicry, matrix metalloproteinase, anti-vasculogenic mimicry therapy
GBC-SD cells and xenografts were determined, respectively. The results showed that expression of MMP-2 and MT1-MMP in human GBCs, GBC-SD cells and xenografts was significantly related to VM in GBCs; a shorter survival time of VM-positive patients with high expression of MMP-2 or MT1-MMP compared to that of the patients with low expression. After treatment with NCTD+TIMP-2, tumor growth, $\mathrm{VM}$ formation, VM hemodynamic of the xenografts in vivo were significantly inhibited as compared to control, NCTD or TIMP-2 group, with a prolonged survival time of the xenograft mice (log-rank test, $\mathrm{P}=0.0115$ ); and these observations were confirmed by VM-like networks by 3-D matrices and showed that proliferation, apoptosis, invasion, migration of GBC-SD cells in vitro were markedly affected. Furthermore, expression of MMP-2 and MT1-MMP in VM formation of the xenografts in vivo and GBC-SD cells in vitro was downregulated as compared to control, NCTD or TIMP-2 group. Thus, we concluded that NCTD enhances TIMP-2 antitumor and anti-VM activities in GBCs through downregulating MMP-2 and MT1-MMP.

\section{Introduction}

Gallbladder cancer (GBC) is the most common malignancy of the biliary tract with highly aggressive characteristics, low 5-year survival and poor prognosis. Because of disappointing surgical resection and chemoradiotherapy, and an effective tumor microcirculation, novel adjuvant therapies for highly aggressive GBCs are clearly needed (1-5). Recent studies have shown that an effective tumor microcirculation in a highly aggressive malignancy, e.g., melanoma, consists of vasculogenesis, angiogenesis and vasculogenic mimicry (VM) $(6,7)$. Therefore, many researchers are currently seeking to develop new angiogenic and/or VM inhibitors from cleaved proteins, monoclonal antibodies, synthesized small molecules and natural products (8-14). However, the sole use of some angiogenic inhibitors has been confirmed to have no effect on VM (15-17). Thus, it should be considered to develop new anti-vascular therapeutic agents that target both angiogenesis and VM, in a special, anti-VM therapy for tumor VM. 
Matrix metalloproteinases (MMPs) including soluble MMPs and membrane-type MMPs (MT-MMPs) are a broad family of zinc-binding endopeptidases that participate in the extracellular matrix (ECM) degradation that accompanies cancer cell invasion, metastasis, and angiogenesis $(18,19)$. Recent studies have indicated that expression of MMP-2 and membrane type 1-MMP (MT1-MMP) was significantly related to VM formation in melanoma and ovarian cancer cells in three-dimensional (3-D) culture; MMP-2 and MT1-MMP were more highly expressed in aggressive melanoma with VM channels compared with poorly aggressive melanoma with absence of VM (20-22). As a 21-kDa protein which selectively forms a complex with the latent proenzyme form of the $72-\mathrm{kDa}$ type IV collagenase, tissue inhibitor of matrix metalloproteinase-2 (TIMP-2) inhibits the type IV collagenolytic activity and the gelatinolytic activity, and abolishes the hydrolytic activity of all members of the metalloproteinase family, thus is a potent inhibitor of cancer cell invasion through reconstituted ECM (23). Addition of endogenous inhibitor TIMP-2 or antibodies to 72-kDa type IV collagenase or specific antiserum against the $72-\mathrm{kDa}$ type IV collagenase achieved alteration of the type IV collagenase-inhibitor balance, then inhibited HT-1080 cell invasion (23). TIMP-2 may effectively inhibit all of the proteolytic activities associated with MMP-2 and/or MT1-MMP, and is sufficient to prevent formation of VM-like patterned networks (24). Thus, TIMP-2 is considered to have anti-VM activity for VM in some highly aggressive malignant tumors.

We recently reported that VM exist in human GBCs, the 3-D matrices and the xenografts of highly aggressive GBC-SD cells, and correlated with the poor prognosis (25-27); that the formation of VM in GBCs is through the activation of the phosphoinositide 3-kinase (PI3-K)/MMPs/Ln-5 $\gamma 2$ and the ephrin type-A receptor 2 (EphA2)/focal adhesion kinase (FAK)/Paxillin signaling pathways in vitro and in vivo; and that recombinant TIMP-2 retarded patterned VM formation in GBC-SD cell 3-D matrices and xenografts as compared to untreated GBC-SD cells and xenografts (28). Norcantharidin (NCTD), a demethylated and low-cytotoxic derivative of cantharidin, not only inhibits the proliferation and growth of a variety of human tumor cells and is used clinically to treat some human cancers because of its anticancer activity, fewer side-effects and leukocytosis (29-34), but also has multiple antitumor activities for GBCs in vitro and in vivo (10,35-38). In this study, we further investigated that expression of MMP-2 and MT1-MMP among human GBC specimens, the 3-D matrices and the nude mouse xenografts of GBC-SD cells was related to VM in GBCs, and the anti-VM activity of NCTD in combination with TIMP-2 for human GBCs, so as to explore if NCTD would serve as a potential anti-VM agent or synergist of cancer therapies. As McNamara et al have pointed out, the future therapeutic spectrum for GBC will likely encompass novel combinations of targeted therapies with cytostatics in scientifically and molecularly directed schedules, thus permitting fewer mechanisms of escape for tumor cells (39).

\section{Materials and methods}

Tissue specimens and human GBC VM identification. This study in human GBC tissue specimens was carried out with approval from the Ethics Committee of Tongji Hospital, Tongji University School of Medicine (Shanghai, China) (Reference no. TER 2012-158); and because this study involved medical records and biological specimens obtained from previous clinical diagnosis and treatment, and two-time using of the medical records and biological specimens, the Ethics Review Committee waived informed consent and the need for written informed consent from the participants, according to the ethical principles and related clauses of the Ministry of Health of P.R. China 'Ethical Review Methods of Biomedical Research Involving Human Subjects (2007)', the World Medical Association (WMA) 'Declaration of Helsinki' and Council for International Organizations of Medical Sciences (CIOMS) 'International Ethical Guidelines for Biomedical Research Involving Human Subjects (2002)'.

For this study, we retrospectively selected 94 GBC patients who underwent curative resection from January, 1994 to August, 2005 at Tongji Hospital of Tongji University School of Medicine. No patients had history of chemotherapy or radiotherapy before surgery. Clinical outcome was followed from the date of surgery to the date of death or until the end of August 31, 2005. Cases lost during follow-up were regarded as censored data for the survival analysis. Finally, 89 resection specimens with complete clinical and prognostic data were collected for analysis. The diagnosis of these GBC samples was verified by two different pathologists who were blinded to the clinical status of patients. The median follow-up period for all patients was 20.16 (range, 1.5-60) months. Identifications of VM in human GBCs by using hematoxylin and eosin (H\&E) and $\mathrm{CD}_{31}$-PAS double staining were performed as described previously (25).

Detections of MMP-2, MT1-MMP in human GBC specimens. Expression of MMP-2, MT1-MMP in human GBC specimens was determined by immunohistochemistry (IHC) as described previously (40). After pre-treating the samples, slides $(4 \mu \mathrm{m})$ were incubated with the primary antibodies MMP-2 (rabbit polyclone, 1:200; Zeta Corporation, Sierra Madre, CA, USA) and MT1-MMP (rabbit monoclonal, 1:100; Abcam, Cambridge, MA, USA), biotinylated secondary antibody (goat anti-rabbit Envision kit; Genentech, San Francisco, CA, USA), 3,3'-diaminobenzidine (DAB), and counter-stained by hematoxylin. Negative controls were established by replacing the primary antibody with phosphate buffer solution (PBS) in all samples, known immunoassaying-positive sections were used as positive controls. To evaluate precisely expression of MMP-2 and MT1-MMP proteins, the computer-assisted image analysis and the selection of cut-off scores were used respectively. All IHC-stained sections were examined in a Zeiss photomicroscope (Carl Zeiss, Inc., Thornwood, NY, USA) equipped with a three-chip charge-coupled device color camera (model DXC-960 MD; Sony Corp., Tokyo, Japan). High-resolution $(1,024 \times 1,024$ pixels) images were obtained from each histospot at $\mathrm{x} 40$ magnification and stored digitally in a computer. The image analysis to quantify intensity of color reaction was analyzed using Image-Pro Plus Software (IPP version 4.5; Media Cybernetics, Inc., Carlsbad, CA, USA), i.e., by computer-assisted image analysis $(41,42)$. The staining intensity levels of MMP-2 and MT1-MMP were measured using arbitrary unit (AU) on a linear scale ranging from 
0 (non-detectable) to 255 (highest intensity). Mean density of five different fields in each zone were quantified by a reader blinded to the clinical outcome. Furthermore, cut-off scores for MMP-2 and MT1-MMP expression were selected based on receiver operating characteristic (ROC) curve analysis $(43,44)$. The area under curve (AUC) via the ROC curve analysis was calculated, respectively, to estimate the discriminatory power of MMPs protein over the entire range of scores for overall survival (OS) rate of GBC patients. The ROC curve was generated and analyzed using MedCalc statistical software package 11.0.1 (MedCalc Software bvba, Ostend, Belgium).

Tumor xenograft assay and survival analysis in vivo. This study was carried out in accordance with the official recommendations of the Chinese Community Guidelines and the Animal Research: Reporting of In Vivo Experiments (ARRIVE) guidelines (45), and was approved by the Ethics Committee of Animal Experiments of Tongji Hospital, Tongji University School of Medicine, and the Science and Technology Commission of Shanghai Municipality (Shanghai, China) (Permit no.: SYXK 2012-0031).

Specific pathogen-free 4-5-week-old Balb/c nu/nu mice and xenograft mice model established by subcutaneous injection of GBC-SD (a highly aggressive human GBC cell line) cells into the right backs of mice were used in this study as described previously $(27,38)$. The mice, by 2 weeks when a tumor xenograft $\left(\sim 200 \mathrm{~mm}^{3}\right)$ was apparent in all mice, were randomly divided into a control group $(n=20)$ receiving intraperitoneal (i.p.) injection of $0.1 \mathrm{ml}$ normal saline alone twice each week, a NCTD group $\{n=20$; each mouse receiving i.p. injection of $28 \mathrm{mg} / \mathrm{kg}$ NCTD [Injection solution, $5 \mathrm{mg} \cdot \mathrm{ml}^{-1}$; Jiangsu Kangxi Pharmaceutical Works, Jiangsu, China; a dose of NCTD $1 / 5 \mathrm{LD}_{50}(10)$ ] given in $0.1 \mathrm{ml}$ of normal saline\}, a TIMP-2 group $[n=20$; each mouse receiving intratumoral (i.t.) injection of $100 \mathrm{nM}$, i.e., $5 \mathrm{mg} / \mathrm{kg}$ recombinant TIMP-2 (Sigma-Aldrich, Seelze, Germany)], and a NCTD+TIMP-2 group ( $n=20$; each mouse receiving i.p. injection of $28 \mathrm{mg} / \mathrm{kg}$ NCTD and i.t. injection of $5 \mathrm{mg} / \mathrm{kg}$ recombinant TIMP-2), twice each week for 6 weeks in total. The xenograft size, i.e., the maximum diameter (a) and minimum diameter (b) were measured with calipers two times each week. Of each group of the xenograft mice $50 \%$ was sacrificed under anesthesia at 8 weeks after injection, and tumor growth including tumor volume, tumor growth curve and tumor inhibitory rate were, respectively, evaluated as described previously $(27,38)$. The other xenograft mice continued to be housed in specific pathogen-free condition, and the mouse survival was evaluated as described previously (38). The outcome was followed from the date of injection to the date of mouse death or until 180th day after inoculation, when the mice still alive were euthanized under anesthesia. The median follow-up period for mice was 15 (range, 3-31) weeks.

VM formation assay of the xenografts in vivo. VM formation assay from GBC-SD nude mouse xenograft sections of each group was conducted by using $\mathrm{H} \& \mathrm{E}$ and $\mathrm{CD}_{31}$-PAS double staining and transmission electron microscopy (TEM) $(27,28)$. For H\&E staining, paraffin-embedded tissue specimens were deparaffinized, hydrated, and stained with $\mathrm{H} \& \mathrm{E}$. For $\mathrm{CD}_{31}$-PAS double staining, sections $(4 \mu \mathrm{m})$ were pre-treated, then incubated in turn with mouse monoclonal anti- $\mathrm{CD}_{31}$ protein IgG (1:50; Lab Vision/NeoMarkers, Fremont, CA, USA), goat anti-mouse Envision kit (Genentech), DAB chromogen, $0.5 \%$ periodic acid solution, followed by treating with Schiff solution in dark chamber, counterstained with hematoxylin, and observed under a light microscope (Olympus IX70; Olympus, Tokyo, Japan). For TEM, fresh samples $\left(0.5 \mathrm{~mm}^{3}\right)$ were fixed in cold $2.5 \%$ glutaraldehyde in $0.1 \mathrm{~mol} \cdot \mathrm{l}^{-1}$ of sodium cacodylate buffer and post-fixed in a solution of $1 \%$ osmium tetroxide, dehydrated, and embedded in a standard fashion. The specimens were then embedded, sectioned, and stained by routine means for a JEOL 1230 TEM (JEOL, Ltd., Tokyo, Japan). All experiments were performed in triplicate.

Hemodynamic assay of the xenograft VM in vivo. Hemodynamic assay of GBC-SD nude mouse xenografts was examined by dynamic micro-magnetic resonance angiography (micro-MRA) (MRI is a $1.5 \mathrm{~T}$ superconductive magnet unit from Marconi Medical Systems, Inc., Cleveland, $\mathrm{OH}$, USA) as described previously (27). The anesthetized xenograft mice ( $n=3,7$-weeks old, $35 \pm 3 \mathrm{~g}$ ) placed at the center of the coils were injected i.v. in the tail vein with human adult serum gadopentetic acid dimeglumine salt injection [HAS-Gd-DTPA, $0.50 \mathrm{mmol}(\mathrm{Gd}) \cdot \mathrm{ml}^{-1}, \mathrm{Mr}=60-100 \mathrm{kDa}, 0.1 \mathrm{mmol}(\mathrm{Gd}) \cdot \mathrm{kg}^{-1}$; Bayer Schering Pharma AG, Berlin, Germany] before sacrifice. Micro-MRA was performed to analyze hemodynamics in the VM (central tumor) regions (28). The images were acquired before injection of the contrast agents and 5, 10, and $15 \mathrm{~min}$ after injection. Three regions of interset (ROI) in the central area and the marginal area of the xenografts were observed and time-coursed pixel numbers per $\mathrm{mm}^{3}$ were counted. Two experiments were performed on these three gated ROI. The data were obtained directly from the MRA analyzer and are expressed as the mean $\pm \mathrm{SD}$.

Vasculogenic-like network assay of the 3-D matrices in vitro. Matrigel and rat-tail type I collagen 3-D matrices were prepared as described previously (27). GBC-SD cells were allowed to adhere to matrix, and untreated (control group) and treated with $28 \mu \mathrm{g} \cdot \mathrm{ml}^{-1}$ NCTD [a dose of NCTD 1/2 $\mathrm{IC}_{50}$ (36), NCTD group], $100 \mathrm{nM}$ recombinant TIMP-2 (Sigma-Aldrich; TIMP-2 group), or $28 \mu \mathrm{g} \cdot \mathrm{ml}^{-1} \mathrm{NCTD}$ and $100 \mathrm{nM}$ recombinant TIMP-2 (NCTD+TIMP-2 group) for 2 days. The ability of GBC-SD cells to engage in VM was respectively analyzed using H\&E staining and periodic acid-Schiff (PAS) staining (without hematoxylin counterstain) and TEM $(27,28)$. The outcome was observed under a light microscope. The images were taken digitally using a Zeiss Telaval Inverted Microscope (Carl Zeiss, Inc.) and camera (Nikon, Tokyo, Japan) at the time indicated. And, the 3-D culture specimens were fixed, dehydrated, embedded, sectioned, and stained by above routine means for a JEOL 1230 TEM. All experiments were performed in triplicate.

Assays of proliferation, apoptosis, invasion and migration of the cells in vitro. The cultured GBC-SD cell suspensions were used for proliferation assay via tetrazolium-based colorimetric method (MTT) and apoptosis assay via flow cytometry (FCM) in vitro. Cells cultured in a 96-well plate $\left(3 \times 10^{5}\right.$ cells $\left./ \mathrm{ml} \cdot 100 \mu \mathrm{l} / \mathrm{well}\right)$ in fresh culture medium at 
$37^{\circ} \mathrm{C}$ in $5 \% \mathrm{CO}_{2}$ were untreated (control group) and treated with $28 \mu \mathrm{g} \cdot \mathrm{ml}^{-1}$ NCTD [a dose of NCTD $1 / 2 \mathrm{IC}_{50}$ (36), NCTD group], $100 \mathrm{nM}$ recombinant TIMP-2 (Sigma-Aldrich; TIMP-2 group), or $28 \mu \mathrm{g} \cdot \mathrm{ml}^{-1} \mathrm{NCTD}$ and $100 \mathrm{nM}$ recombinant TIMP-2 (NCTD+TIMP-2 group) for 5 days. The inhibitory effect of each group on proliferation of GBC-SD cells was determined by MTT assay as described previously (38). For FCM, cells were untreated (control group) or treated with above NCTD, TIMP or NCTD+TIMP-2 (6 wells per agent) at $37^{\circ} \mathrm{C}$ in $5 \% \mathrm{CO}_{2}$ for $24 \mathrm{~h}$, then were made up into the cell suspension $\left(5 \times 10^{5}\right.$ cells $\left./ \mathrm{ml}\right)$, and suspended in $500 \mu 1$ binding buffer. Tumor DNA was then stained for 15 min with $5 \mu \mathrm{l}$ Annexin V-FITC and propidium iodine (PI) (Sigma, St. Louis, MO, USA). DNA value and apoptotic rate were determined by the Cell Apoptotic Detection kit (BioDev, Beijing, China) and the Fluorescent Activated Cell Sorter (420 type FCM; Becton-Dickinson, San Jose, CA, USA). Three experiments were separately performed.

The 35-mm, 6-well Transwell membranes (Coster, South Elgin, IL, USA) were used to measure the invasiveness of GBC-SD cells in vitro as described (38). Upper wells of chamber were filled with $1 \mathrm{ml}$ serum-free DMEM containing $2 \times 10^{5} \mathrm{ml}^{-1}$ GBC-SD cells $(\mathrm{n}=3)$. Cells were untreated (control group) and treated, respectively, with the above NCTD, TIMP-2 or NCTD+TIMP-2 in fresh culture medium $(0.3 \mathrm{ml} / \mathrm{every}$ chamber) for $24 \mathrm{~h}$. Lower wells of the chamber were filled with $3 \mathrm{ml}$ serum-free DMEM containing $1 \mathrm{X}$ MITO+ (Collaborative Biomedical Prdts, Bedford, MA, USA). Cells invaded through the basement membrane were stained with $\mathrm{H} \& \mathrm{E}$, and counted under a light microscope. Invasiveness was calculated as the number of cells invaded successfully through the matrix-coated membrane to the lower wells by counting cells in five independent microscopic fields. All experiments were performed in triplicate with consistent results.

Collagen gel suspensions for GBC-SD cells are prepared by mixing $250 \mu \mathrm{l}$ of a suspension $\left(3 \times 10^{6} \mathrm{ml}^{-1}\right)$ into $250 \mu \mathrm{l}$ of undiluted rat-tail collagen type I (Sigma-Aldrich) dripped into sterilized $35-\mathrm{mm}$ petri dishes that contained $2 \mathrm{ml}$ culture medium to prevent adhesion of the collagen to the glass substrate. Cells were treated according to above invasion assay. Gel contraction was defined as the relative change in the gel size, measured daily in two dimensions including maximum and minimum diameters. Contraction index (CI) was calculated, i.e., migration assay, as follows: $\mathrm{CI}=1-\left(\mathrm{D}-\mathrm{D}_{0}\right)^{2} \times 100 \%$, where $D$ is the primary diameter of rat-tail collagen type $I, D_{0}$ is the average of maximum and minimum diameters of gel. All experiments were performed in triplicate.

Detection of MMP-2 and MM1-MMP molecules from $G B C-S D$ cells in vitro and xenografts in vivo. Expression of MMP-2 and MM1-MMP proteins/mRNAs from GBS-SD nude mouse xenografts in vivo and 3-D matrices of GBS-SD cells in vitro were determined by streptavidin-biotin complex method (SABC), immunofluorescence, western blotting and semiquantitative reverse transcription-polymerase chain reaction (RT-PCR), respectively, as described previously (28).

For SABC, sections were incubated in turn with primary antibody [MMP-2 (1:200), MT1-MMP (1:100), rabbit polyclonal antibody], biotinylated secondary antibody, SABC reagents and DAB solution (all from Wuhan Boster Biological
Technology, Ltd., Wuhan, China), and observed under an optic microscope (Olympus CH-2; Olympus). Negative controls were established by replacing the primary antibody with PBS in all samples. Ten sample slides (10 visual fields per slide) in each group were selected by analysis.

For indirect immunofluorescence, sections were added in order with $50 \mu \mathrm{l}(1: 100)$ primary antibody (MMP-2 and MT1-MMP, rabbit polyclonal antibody; Wuhan Boster Biological Technology, Ltd.), biotinylated secondary antibody (1:100, goat anti-rabbit IgG-FITC/GGHL-15F; Immunology Consultants Laboratory, Portland, OR, USA), mounted in coverslip using buffer glycerine, and observed under a fluorescence microscope (Nikon). The slides were treated with PBS in place of primary antibody as negative control. Ten sample slides (10 visual fields per slide) in each group were chosen by analysis. Expression of each protein on slides of the xenografts showed a yellow-green fluorescent stain. Fluorescence stain intensity was classed into,,,,,- \pm++++++++++ . Then grouped as, - to + : negative expression, $\geq++$ : positive expression.

For western blotting, cells were lysed, the supernatant was recovered, BCA protein was determined with a protein quantitative kit (KangChen KC-430; KangChen Bio-tech, Shanghai, China). Then, an aliquot of $20 \mu \mathrm{g}$ of proteins was subjected to sodium dodecyl sulfate-polyacrylamide gel electrophoresis (SDS-PAGE) under reducing conditions, and were then transferred to a PVDF membrane. The membrane was added in order with each primary antibody (MMP-2, MT1-MMP: mouse anti-human antibody, 1:3,000; Wuhan Boster Biological Technology, Ltd.), mouse anti-human GAPDH antibody $(1: 10,000)$, and an appropriate anti-mouse HRP-labeled secondary antibody (1:5,000; both from KangChen Bio-tech). The target proteins were visualized by an enhanced chemiluminescent reagent $\left(\mathrm{KC}^{\mathrm{TM}}\right.$ Chemiluminescent kit, KangChen KC-420; KangChen Bio-tech), imaged on the Bio-Rad chemiluminescence imager. The gray value and gray coefficient ratio of every protein were analyzed and calculated with ImageJ analysis software.

For RT-PCR, total RNA from the xenograft cells of each group was prepared using the TRIzol reagent (Invitrogen Life Technologies, Carlsbad, CA, USA). Concentration of RNA was determined by the absorption at $260-280 \mathrm{~nm}$. PCR amplifications were performed with gene-specific primers as below with annealing temperature and number of amplification cycles optimized using cDNA from the xenograft cells in each group. The primers for MMP-2, MM1-MMP and GAPDH were as follows: MMP-2 (290 bp) 5'-TCT GAG GGT TGG TGG GAT TGG-3' (sense), 5'-AAG AGC GTG AAG TTT GGA AGC A-3' (anti-sense); MM1-MMP (180 bp) 5'-CAA AGG CAG AAC AGC CAG AGG-3' (sense), 5'-ACA GGG ACC AAC AGG AGC AAG-3' (anti-sense); GAPDH (211 bp) 5'-CCT CTA TGC CAA CAC AGT GC-3' (sense), 5'-GTA CTC CTG CTT GCT GAT CC-3' (anti-sense). PCR amplification reactions were performed as follows: 1 cycle of $94^{\circ} \mathrm{C}$ for $5 \mathrm{~min} ; 35$ cycles of $94^{\circ} \mathrm{C}$ for $10-22 \mathrm{sec}, 57-60^{\circ} \mathrm{C}$ for $15-20 \mathrm{sec}$, $72^{\circ} \mathrm{C}$ for $20 \mathrm{sec}, 82-86^{\circ} \mathrm{C}$ (fluorescence collection) for 5-10 sec; 1 cycle of $72-99^{\circ} \mathrm{C}$ for $5 \mathrm{~min}$. GAPDH primers were used as control for PCR amplication. PCR products $(10 \mu \mathrm{l})$ were placed onto $15 \mathrm{~g} \cdot l^{-1}$ agarose gel and observed by ethidium bromide (Huamei Bioengineering Co., Ltd., Shanghai, China) staining using ABI Prism 7300 SDS software. 
A
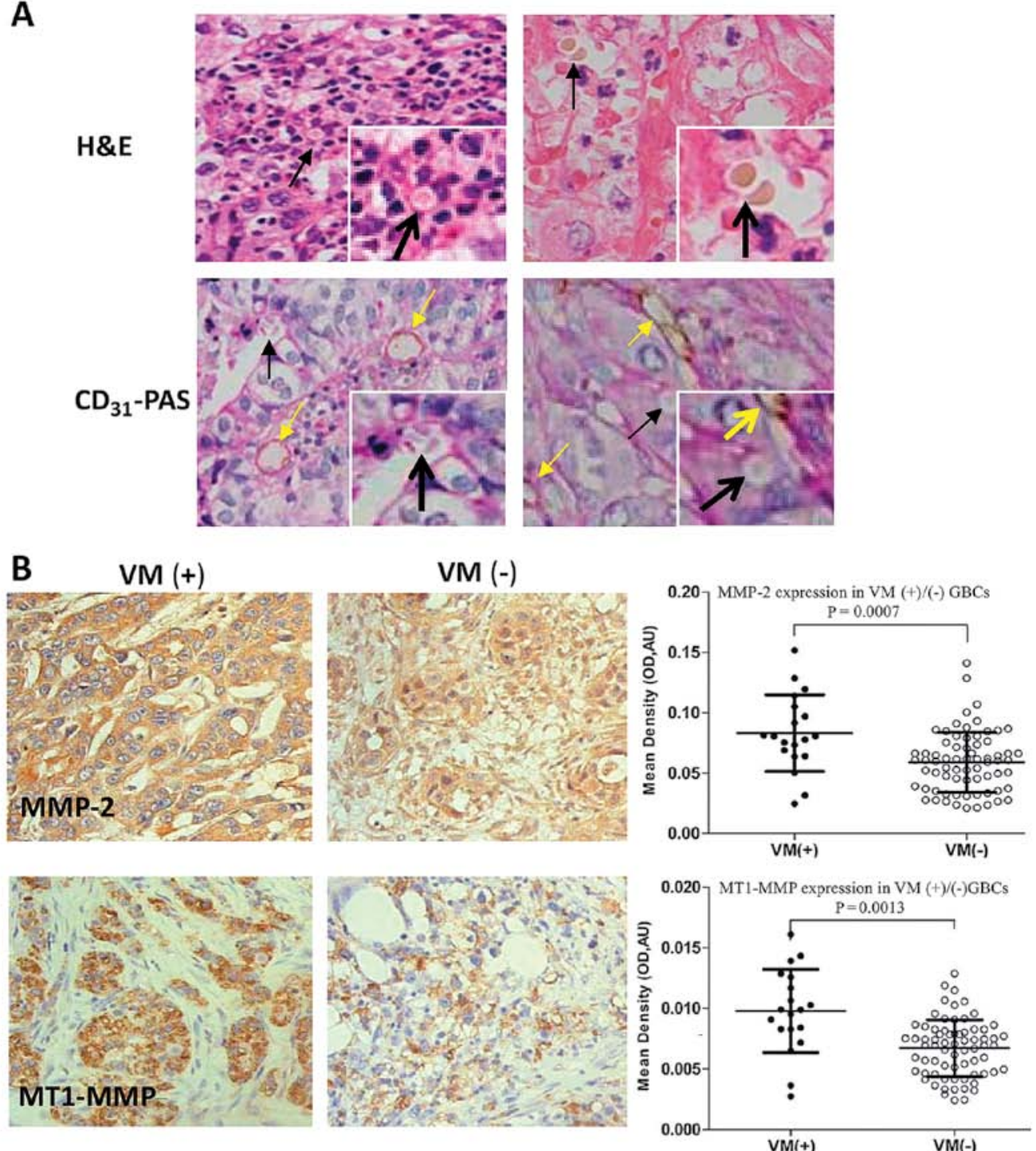

$\mathrm{C}_{1}$

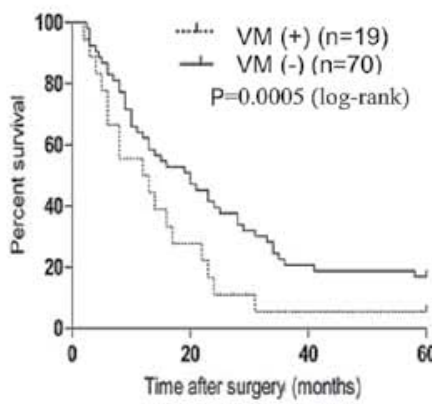

\section{$\mathrm{C}_{2}$}

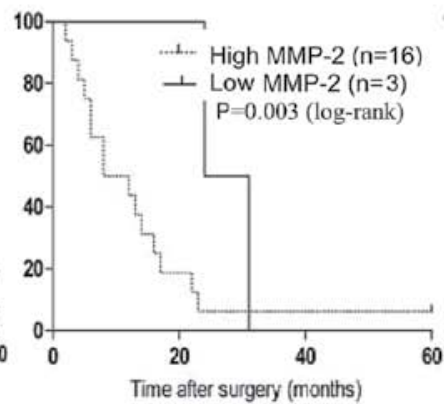

$\mathrm{C}_{3}$

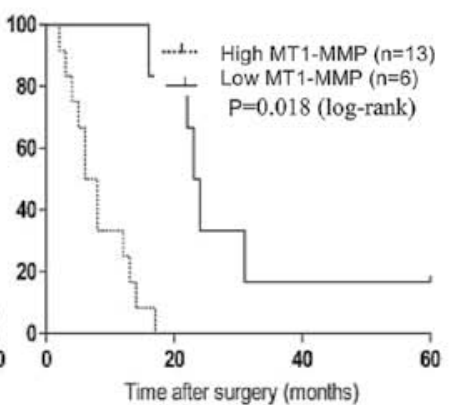

Figure 1. Relationship between vasculogenic mimicry (VM) and matrix metalloproteinase (MMP)-2 or membrane type 1-MMP (MT1-MMP) expression in human gallbladder cancers (GBCs). (A) Morphologic appearance of VM (Envision, original magnification, $\mathrm{x} 400$ ) with hematoxylin and eosin (H\&E) staining and $\mathrm{CD}_{31}$-PAS double staining: The VM channels (black arrows) positive for periodic acid-Schiff (PAS) staining were lined only by $\mathrm{CD}_{31}$-negative tumor cells lining the external wall, single or several erythrocytes therein, and $\mathrm{CD}_{31}$-positive endothelium-dependent vessels (yellow arrows) presenting in the same field with VM. (B) Expression of MMP-2, MT1-MMP in VM (+)/(-) GBC samples (Envision, original magnification, x400). The positive expression site of MMP-2 or MT1-MMP protein presented yellow-brown reactant was in cytoplast or both cytoplast and cytomembrane. Expression of MMP-2 and MT1-MMP proteins was significantly higher in VM (+) GBCs than that of VM (-) GBCs (P=0.0007, P=0.0013). (C) Kaplan-Meier survival curves (log-rank test) for VM (+)/(-) GBC patients, high or low expression of MMP-2 or MT1-MMP. The survival time of VM (+) GBC patients was significantly shorter than that of the VM (-) patients $\left(\mathrm{C}_{1}, \mathrm{P}=0.000\right)$; a worse survival of VM-positive $\mathrm{GBC}$ patients with high MMP-2 $\left(\mathrm{C}_{2}, \mathrm{P}=0.003\right)$ or MT1-MMP $\left(\mathrm{C}_{3}, \mathrm{P}=0.018\right)$ expression than that of the patients with low MMP-2 or MT1-MMP expression.

Statistical analysis. The data are expressed as mean \pm SD and performed using SAS 9.0 software (SAS Institute, Inc., Cary,
NC, USA). The comparison and association between VM and categorical variables were analyzed by $\mathrm{t} / \mathrm{F}$ test and Spearman 


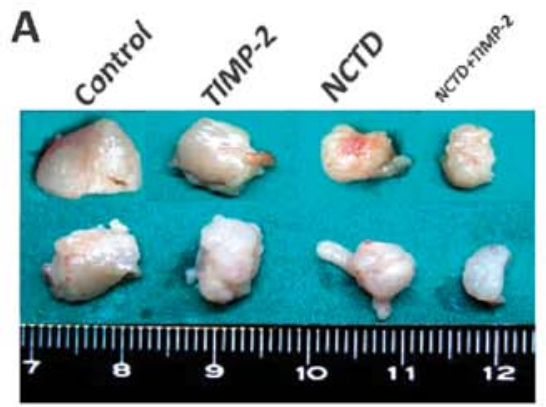

B
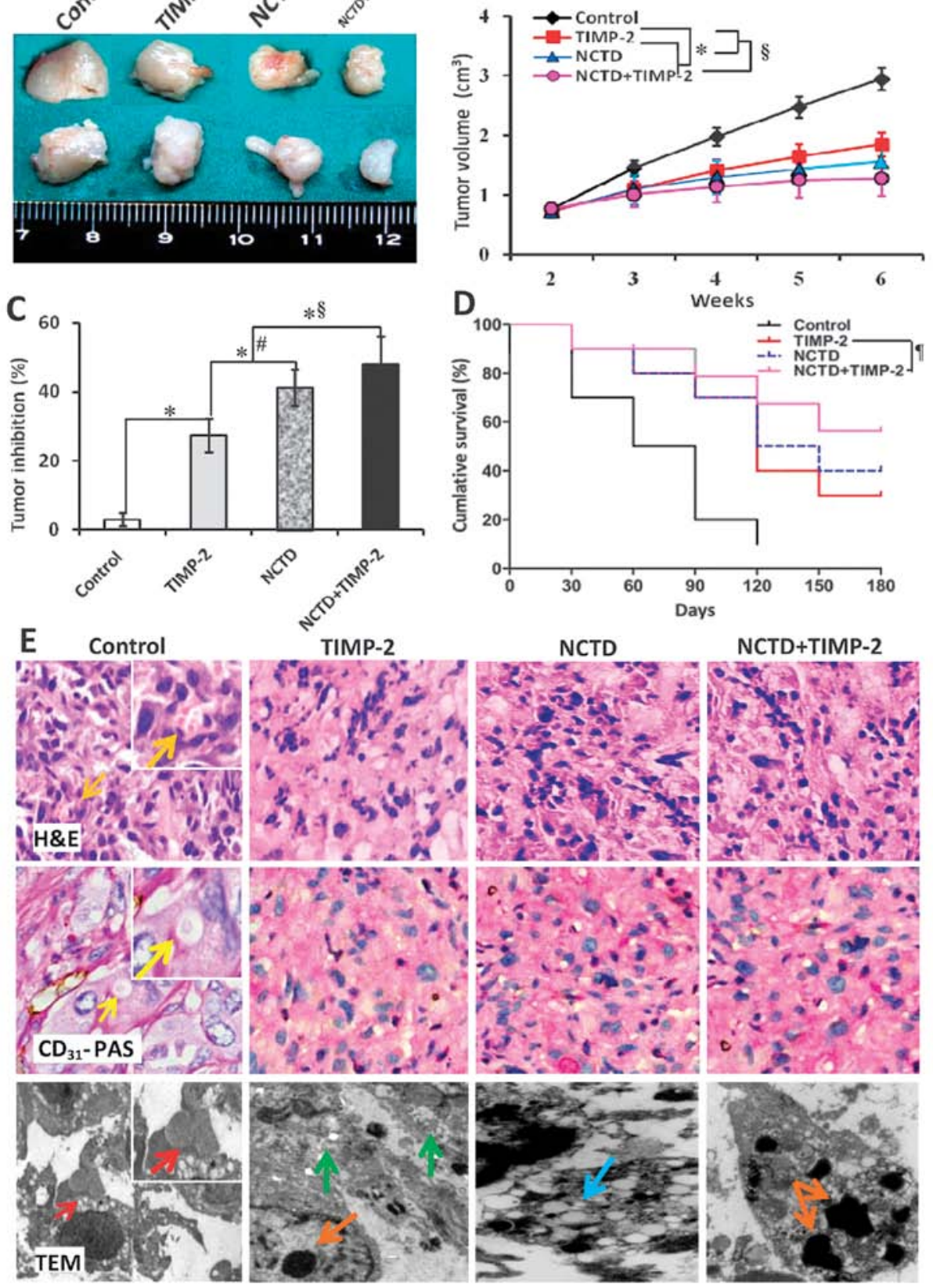

Figure 2. Growth and vasculogenic mimicry (VM) formation of GBC-SD xenografts, and survival of the xenograft mice in vivo. (A-C) The size, volume and tumor inhibition of the xenografts of each group. ${ }^{*} \mathrm{P}<0.001$ vs. control group; ${ }^{*} \mathrm{P}<0.01$ vs. tissue inhibitor of matrix metalloproteinase-2 (TIMP-2) group; ${ }^{\S} \mathrm{P}<0.01$ vs. norcantharidin (NCTD) or TIMP-2 group. (D) Kaplan-Meier survival curves for the xenograft mice of each group (log-rank test, ${ }^{9} \mathrm{P}=0.0115$ vs. control group), whilst no difference on survival time among TIMP-2, NCTD and NCTD+TIMP-2 groups. (E) Histomorphologic appearance of the xenografts of each group. In control group, hematoxylin and eosin (H\&E) staining (original magnification, x200 or x400) showed tumor cell-lined VM channels containing erythrocytes (orange arrows) without any evidence of tumor necrosis; $\mathrm{CD}_{31}$-PAS double staining (original magnification, $\mathrm{x} 200$ or $\mathrm{x} 400$ ) showed periodic acid-Schiff (PAS)-positive substances lining channels and forming basement membrane-like structures (VM) with single erythrocyte inside (yellow arrows); transmission electron microscopy (TEM) (original magnification, $\mathrm{x} 8,000$ ) visualized several erythrocytes at the central of tumor nests in the xenografts (red arrows). However, similar phenomenon failed to occur in the xenografts in TIMP-2, NCTD or NCTD+TIMP-2 group, with destroyed cellular organelles, vacuolar degeneration (blue arrow), cell necrosis (green arrows), nuclear pyknosis, fragmentation and apoptotic bodies (brown arrows).

correlation analysis, respectively. Survival curves were calculated with the Kaplan-Meier method and were compared using the log-rank test. $\mathrm{P}<0.05$ was considered statistically significant.

\section{Results}

$M M P-2$ and MT1-MMP expression relates to VM in GBC patients. We reported that VM existed in human GBCs and corrected with the patient's poor prognosis $(25,26)$. In this experiment, we further investigated if expression of MMP-2 and MT1-MMP proteins relates to VM in GBC patients. As shown in Fig. 1, VM in human GBCs was observed by using H\&E and $\mathrm{CD}_{31}$-PAS double staining (Fig. 1A); expression of MMP-2 and MT1-MMP proteins in VM-positive GBCs was significantly higher than those in VM-negative GBCs (Fig. 1B, P=0.0007 and $\mathrm{P}=0.0013)$. Then, by selecting the cut-off score for high 
or low IHC reactivity and calculating the AUC of MMP-2 or MT1-MMP via ROC curve analysis, 89 GBC specimens were categorized into high and low MMP-2 and MT1-MMP expression groups, respectively. According to high or low expression of MMP-2 (38.6 or 61.4\%) and MT1-MMP (18.6 or 81.4\%) in VM-negative GBCs, and high or low expression of MMP-2 (84.2 or 15.8\%) and MT1-MMP (68.4 or 31.6\%) in VM-positive GBCs, a positive correlation between MMP-2 $(r=0.374$, $\mathrm{P}=0.0003)$ or MT1-MMP $(\mathrm{r}=0.449, \mathrm{P}=0.0001)$ expression and $\mathrm{VM}$ was revealed, respectively. In addition, the means and medians for survival time in VM-positive GBC patients were 11.13 and 9 months as compared to 22.62 and 22 months in VM-negative GBC patients; the cumulative 1-, 3- and 5-year OS rate were $36.84,0$ and $0 \%$ in the VM-positive group and $71.43,21.43$ and $4.29 \%$ in the VM-negative group, respectively. The survival time of VM-positive GBC patients were significantly shorter than that of VM-negative GBC patients (Fig. $1 \mathrm{C}_{1}$, $\mathrm{P}=0.000$ ); a worse survival of VM-positive $\mathrm{GBC}$ patients with high MMP-2 (Fig. $1 \mathrm{C}_{2}, \mathrm{P}=0.003$ ) or MT1-MMP (Fig. $1 \mathrm{C}_{3}$, $\mathrm{P}=0.018$ ) expression than that of the patients with low MMP-2 or MT1-MMP expression. Thus, expression of MMP-2 and MT1-MMP was considered to significantly relate to VM in human GBCs and prognosis of GBC patients with VM.

NCTD enhances TIMP-2 antitumor and anti-VM activities for $G B C$-SD nude mouse xenografts in vivo. We have reported that TIMP-2 has anti-VM activity for human GBC cells (28). Here, we investigated whether NCTD enhances TIMP-2 anti-VM activity for human highly aggressive GBCs. In this experiment, GBC-SD xenografts were seen in all nude mice at the end of the second week after inoculation. The xenograft volume was markedly decreased, tumor inhibition was significantly increased in TIMP-2, NCTD or NCTD+TIMP-2 group as compared to control group (Fig. 2A-C, all $\mathrm{P}<0.001$ ); but the xenograft volume was much lower, tumor inhibition was much higher in NCTD+TIMP-2 group than those in NCTD or TIMP-2 group (Fig. $2 \mathrm{~A}-\mathrm{C}$, all $\mathrm{P}<0.01$ ). Furthermore, a prolonged survival time of the xenograft mice in NCTD, TIMP-2 or NCTD+TIMP-2 group was observed when compared with control group (Fig. 2D, log-rank test, $\mathrm{P}=0.0115$ ), whilst without difference on survival time among TIMP-2, NCTD and NCTD+TIMP-2 groups.

In addition, in control group, H\&E staining showed VM channels formed by tumor cells and erythrocytes therein; $\mathrm{CD}_{31}$-PAS double staining showed $\mathrm{CD}_{31}$-negative PAS-positive substance lining channels and forming basement membrane-like structures (VM) with single erythrocyte inside (Fig. 2E); and TEM clearly visualized several erythrocytes at the centrer of the tumor nests and non-vascular structure between the surrounding tumor cells and erythrocytes (Fig. 2E). VM in histology appears multiple, with ECM-rich PAS-positive networks and surrounding clusters of tumor cells, while VM structures were strictly defined as $\mathrm{CD}_{31}$-negative PAS-positive structures (6), thus VM existed in GBC-SD xenografts $(9 / 10,90.0 \%)$. However, microscopically similar phenomenon failed to occur in the xenografts in TIMP-2, NCTD or NCTD+TIMP-2 group, with destroyed cellular organelles, vacuolar degeneration, cell necrosis, nuclear pyknosis, fragmentation and apoptotic bodies; and these inhibited and destroyed microscopical phenomena are more obvious in NCTD+TIMP-2 group than TIMP-2 or NCTD group (Fig. 2E). The results showed that highly aggressive GBC-SD cells were able to form VM networks when injected subcutaneously into the mice, and facilitated xenograft growth; that NCTD+TIMP-2 more effectively inhibited VM formation and tumor growth of the xenografts than NCTD or TIMP-2 in vivo. Thus, we concuded that NCTD enhanced TIMP-2 antitumor and anti-VM activities for GBC-SD nude mouse xenografts in vivo.

NCTD enhances anti-VM activity for GBC-SD nude mouse xenografts through affecting VM hemodynamics in vivo. Two-millimeter interval horizontal scanning of the xenografts was conducted to compare tumor signal intensities of the xenograft mice by dynamic micro-MRA with an intravascular macromolecular MRI contrast agent HAS-Gd-DTPA. As shown in Fig. 3, the xenograft center in control group exhibited a gradually increased multiple high-intensity MRI signal (pixel count $/ \mathrm{mm}^{3}$ ), i.e., higher occurrence of VM observed in the xenograft center, a result correlating with pathological VM (all $\mathrm{P}<0.001)$. However, the center region of the xenografts in TIMP, NCTD or NCTD+TIMP-2 group exhibited a low intensity MRI signal or a lack of signal change in intensity as compared to control group, a result consistent with central ischemic necrosis, disappearance of nuclei, and apoptosis; and these MRI signals were much less in NCTD+TIMP-2 group than TIMP-2 or NCTD group $(\mathrm{P}<0.001)$, no difference on signal intensity was observed between NCTD group and TIMP-2 group. Thus, we deduced that NCTD enhanced antitumor and anti-VM activities for GBC-SD xenografts through affecting VM hemodynamic and inducing the ischemic necrosis of the xenografts in vivo.

NCTD enhances TIMP-2 anti-VM activity for GBC-SD cells through inhibiting VM-like network formation in vitro. To further verify TIMP-2 anti-VM activity enhanced by NCTD, we observed VM-like networks formed in GBC-SD 3-D matrices in vitro. As shown in Fig. 4, in the control group, GBC-SD cells were able to form hollow tubular networks and microstructures when cultured on Matrigel and rat-tail collagen type I; and PAS-positive, cherry-red VM base-membrane materials were found in granules and patches in the cytoplasm of GBC-SD cells appeared around the signal cell or cell clusters by PAS staining without hematoxylin counterstain. But in the process of network formation, using TIMP-2, NCTD or NCTD+TIMP-2 for 2 days, GBC-SD cells lost the capacity of the above VM-like network formation, with visible cell aggregation, float, nuclear fragmentation; using TIMP-2, NCTD or NCTD+TIMP-2 for 2-4 days after network formation, the already formed VM-like networks from GBC-SD 3-D matrices were inhibited or destroyed, with visible cell aggregation, deformed collagen framework, less microvilli, vacuolar degeneration, nuclear fragmentation and typical apoptotic bodies; and more obvious inhibition or destruction of the above forming and formed VM-like structure was observed in NCTD+TIMP-2 group than TIMP-2 or NCTD group (Fig. 4). It was showed that NCTD+TIMP-2 more effectively inhibited and destroyed the forming VM and formed VM in GBC-SD cells in vitro, thus confirmed that NCTD enhanced TIMP-2 anti-VM activity for GBC-SD cells in vitro. 


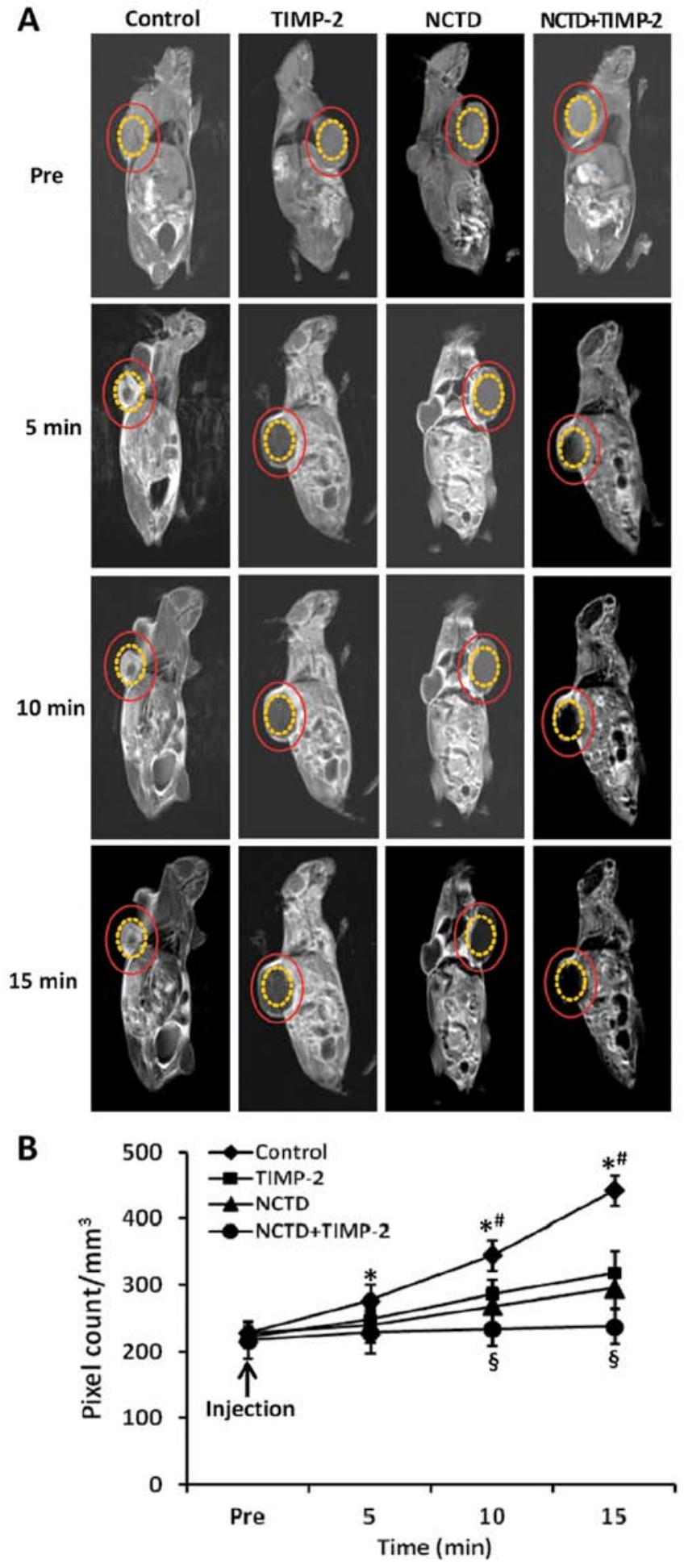

Figure 3. Dynamic micro-magnetic resonance angiography (micro-MRA) and hemodynamic of GBC-SD xenografts in vivo. (A) The images were acquired before the injection (Pre), 5, 10, and 15 min after injection of the contras agents (HAS-Gd-DTPA). The tumor center area (yellow circle) in control group exhibited a gradually increased multiple high-intensity signal (which is consistent with the intensity observed in tumor marginal area between the red circle and the yellow circle). However, the center region (yellow circle) of the xenografts in TIMP, norcantharidin (NCTD) or NCTD+TIMP-2 group exhibited a decreased signal or a lack of signal change in intensity; of them, these MRI signals were much less in NCTD+TIMP-2 group than tissue inhibitor of matrix metalloproteinase-2 (TIMP-2) or NCTD group. (B) Hemodynamic changes of the xenograft vasculogenic mimicry (VM) of each group. All data are expressed as means \pm SD. ${ }^{*} \mathrm{P}<0.001$ vs. Pre injection in control group; ${ }^{*} \mathrm{P}=0.0000$ vs. NCTD or TIMP- 2 group; ${ }^{\circledR} \mathrm{P}<0.001 \mathrm{vs.} \mathrm{NCTD}$ or TIMP-2 group. But, no difference on signal intensity (pixel count $/ \mathrm{mm}^{3}$ ) was observed between NCTD group and TIMP-2 group.
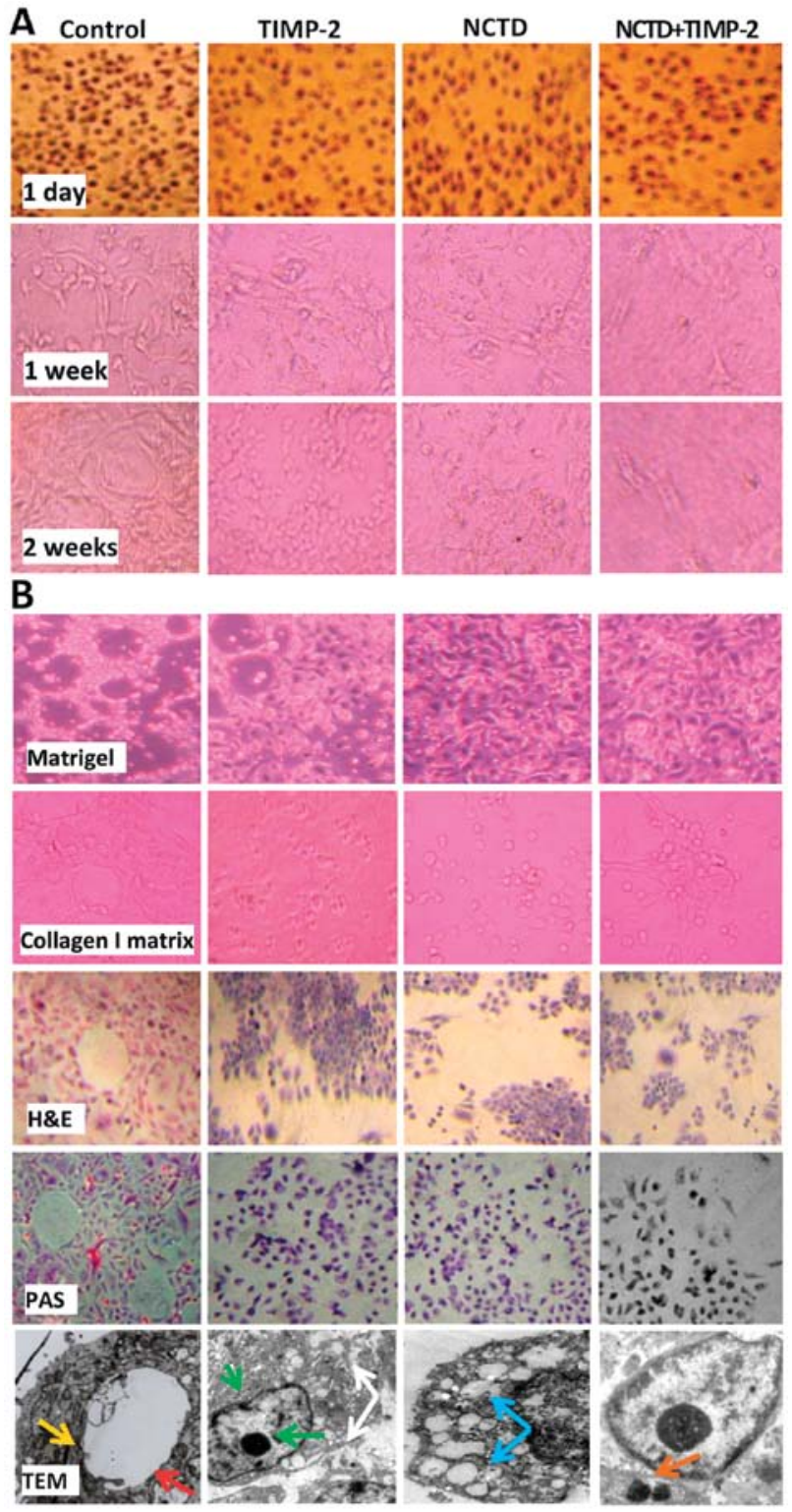

Figure 4. The forming and formed vasculogenic mimicry (VM)-like networks of the 3-D matrix of GBC-SD cells in vitro under a phase contrast microscope and an electron microscope. (A) The forming VM-like networks of the 3-D matrix. GBC-SD cell-formed networks in control group initiated formation within $48 \mathrm{~h}$ after seeding, matured after 1 week, formed optimal VM-like structure by 2 weeks; but in the process of network formation, using tissue inhibitor of matrix metalloproteinase-2 (TIMP-2), norcantharidin (NCTD) or NCTD+TIMP for 2 days, GBC-SD cells lost the capacity of the above VM-like network formation, with visible cell aggregation, float, nuclear fragmentation; and more obvious inhibition of the forming VM-like structure was observed in NCTD+TIMP-2 group. (B) The formed VM-like networks of the 3-D matrix. In control group, GBC-SD cells formed the optimal patterned, VM-like networks when cultured on Matrigel and rat-tail collagen type I matrix [including hematoxylin and eosin (H\&E) staining] for 2 weeks, periodic acid-Schiff (PAS) positive, cherry-red materials found in granules and patches in the cytoplasm appeared around the signal cell or cell clusters by PAS staining without hematoxylin counterstain (original magnification, all x200); and channelized or hollowed VM-like network microstructures visualized under transmission electron microscopy (TEM) (original magnification, $\mathrm{x} 1,200$ ) with clear microvilli surrounding cluster of tumor cells (red arrow), cellular organelle structures, and cell connection with an increased electron density in density (yellow arrow). After this, using TIMP-2, NCTD or NCTD+TIMP-2 for 2-4 days, the already formed VM-like networks from the 3-D matrix were inhibited or destroyed, with visible deformed collagen framework, decreased microvilli, destroyed cellular organelles (white arrows), vacuolar degeneration (blue arrow), nuclear pyknosis and fragmentation (green arrows), and typical apoptotic bodies (brown arrows); and more obvious inhibition or destruction of the formed VM-like structure was observed in NCTD+TIMP-2 group. 

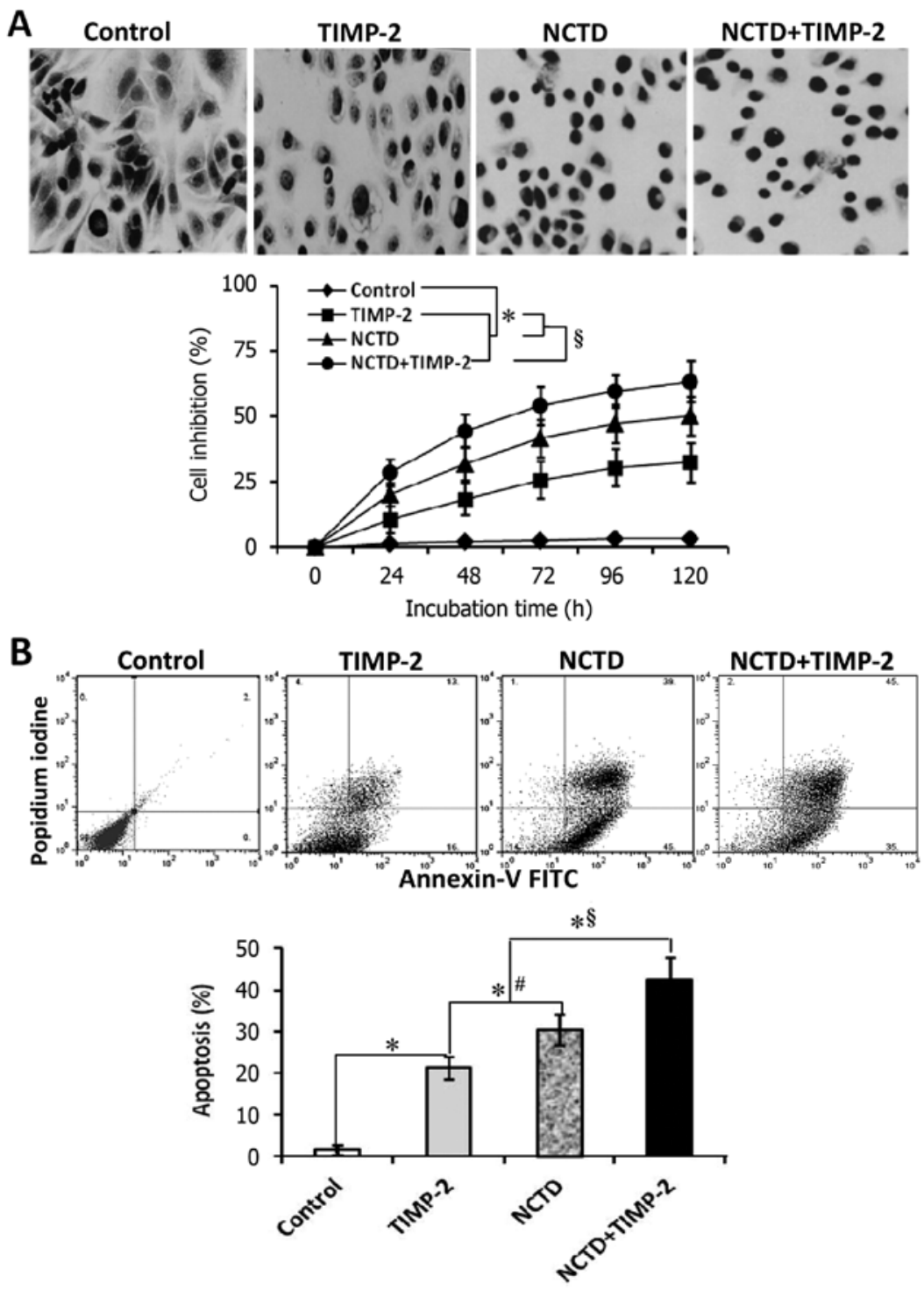

Figure 5. Growth of GBC-SD cells in vitro. (A) Proliferation of GBC-SD cells by tetrazolium-based colorimetric (MTT) assay (original magnification, $\mathrm{x} 400$ ) and the time-response curves. (B) Apoptosis of GBC-SD cells by flow cytometry (FCM) [the right lower quadrant for apoptotic cells (FITC+/PI-) in the scatter diagram]. After treatment with tissue inhibitor of matrix metalloproteinase-2 (TIMP-2), norcantharidin (NCTD) or NCTD+TIMP-2 for $24 \mathrm{~h}$ and with time prolonging, proliferation of GBC-SD cells was significantly inhibited and apoptosis of GBC-SD cell was markedly increased as compared to control group ( $\mathrm{P}<0.001)$, in a time-dependent manner. The proliferative inhibition and apoptotic inducement in NCTD group were higher than those of TIMP-2 group $\left({ }^{\#} \mathrm{P}<0.01\right)$, and were highest in NCTD+TIMP-2 group $\left({ }^{\circledR} \mathrm{P}<0.01\right.$ vs. NCTD or TIMP-2 group).

NCTD enhances TIMP-2 anti-VM activity in GBC-SD cells through disturbing malignant phenotypes in vitro. To confirm that NCTD enhances TIMP-2 anti-VM activity, we further observed the effects of NCTD+TIMP-2 on malignant phenotypes of GBC-SD cells such as proliferation, apoptosis, invasion and migration in vitro. In this experiment, the morphology of treated GBC-SD cells showed visible cell aggregation, float, nuclear fragmentation, cataclysms; and a significant inhibition of cell proliferation in a time-dependent manner was observed in TIMP-2, NCTD or NCTD+TIMP-2 group as compared to control groups (Fig. 5A, all $\mathrm{P}<0.001$ ). These results were confirmed by apoptotic assay and microstructure observation, which revealed that apoptosis percent of GBC-SD cells (total cells under right quadrant of cells) was significantly increased as compared to control group (Fig. 5B, $\mathrm{P}<0.001$ ); decrease in microvillus, cytoplast vacuoles, nuclear shrinkage, chromatin aggregation and typical apoptotic bodies were observed under TEM (Fig. 4B). In addition, the number of invaded GBC-SD cells in TIMP-2, NCTD or NCTD+TIMP-2 group was much less than that of control group (Fig. 6A, all $\mathrm{P}<0.001$ ); a significant decreased gel CI of treated GBC-SD cells was observed as compared to control group from 1 to 4 days (Fig. 6B, all $\mathrm{P}<0.001$ ), without different CI between TIMP-2 group and NCTD group. Interestingly, malignant phenotypes of GBC-SD cells such as proliferation, apoptosis, invasion and migration were significantly influenced in NCTD+TIMP-2 group, i.e., proliferation, invasion and migration of GBC-SD cells were significantly inhibited, apoptosis percent of GBC-SD cells was markedly increased as compared to TIMP-2 or NCTD group (Figs. 5 and 6, $\mathrm{P}<0.01)$. Taken together, these in vitro results indicated that NCTD enhanced TIMP-2 anti-VM activity for GBC-SD cells through disturbing the malignant phenotypes of GBC-SD cells in vitro. 


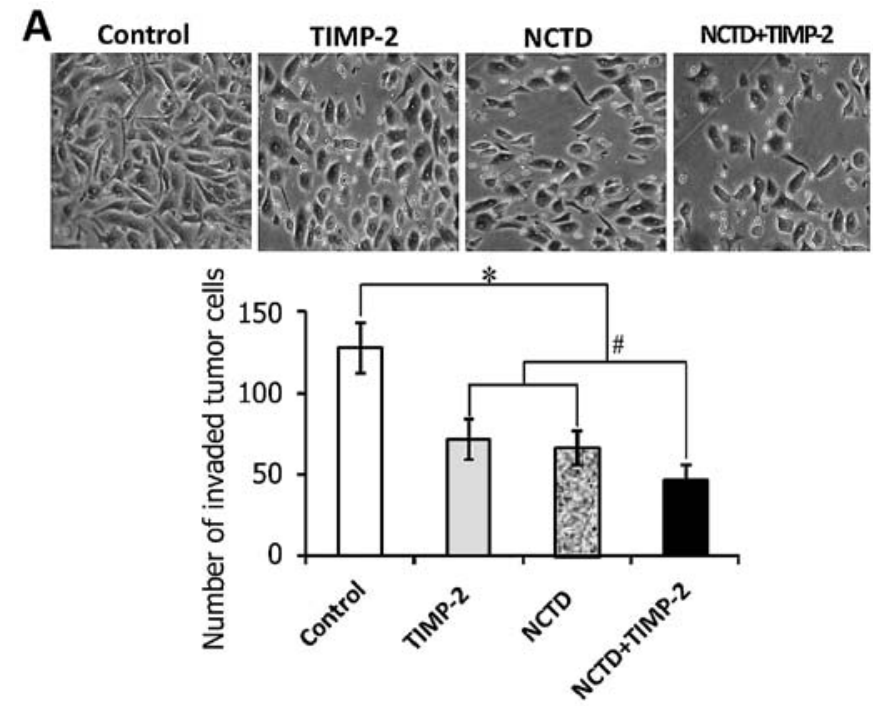

B

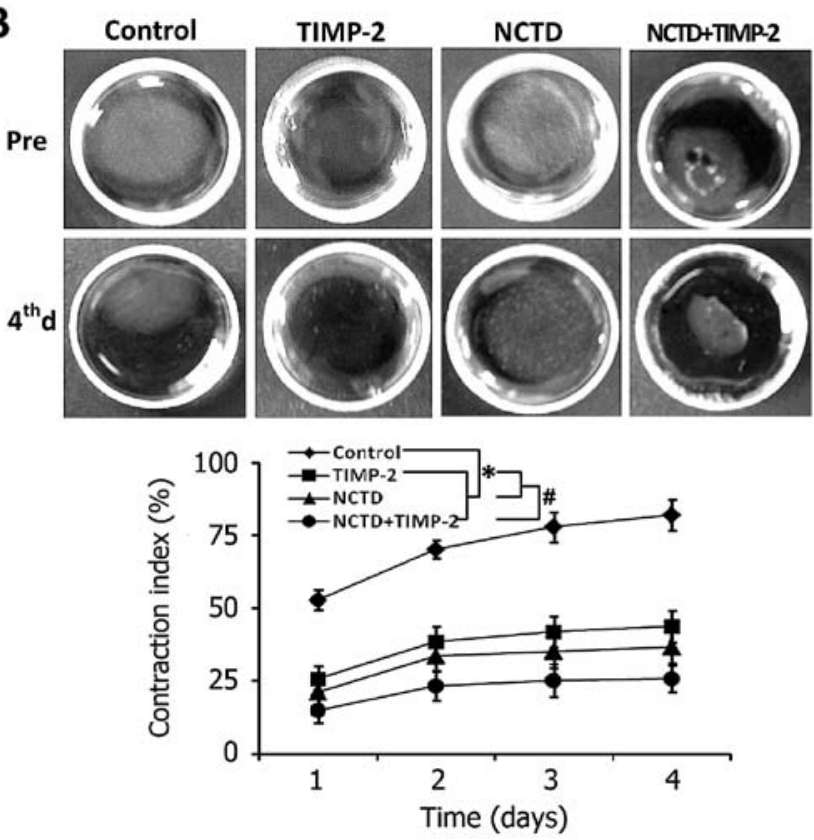

Figure 6. Invasion and migration of GBC-SD cells in vitro. (A) Invasion of GBC-SD cells by Transwell invasion assay with hematoxylin and eosin (H\&E) staining (original magnification, $\mathrm{x} 400$ ). The invaded number of GBC-SD cells in tissue inhibitor of matrix metalloproteinase-2 (TIMP-2), norcantharidin (NCTD) or NCTD+TIMP-2 group was decreased significantly as compared to control group ( $\left.{ }^{*} \mathrm{P}<0.001\right)$; the number of invaded cells in NCTD+TIMP-2 group was much less than that of TIMP-2 or NCTD group $\left({ }^{\#} \mathrm{P}<0.01\right)$. (B) Migration of GBC-SD cells by collagen gel contraction test. Gel contraction index (CI) of GBC-SD cells in TIMP-2, NCTD or NCTD+TIMP-2 group was decreased as compared to control group ( $\mathrm{P}<0.001)$; among them, $\mathrm{CI}$ in NCTD+TIMP-2 group was lowest ("P<0.01 vs. TIMP-2 or NCTD group).

NCTD enhances TIMP-2 anti-VM activity through downregulating expression of MMP-2 and MT1-MMP. The above clinical experiment on human GBCs showed that expression of MMP-2 and MT1-MMP was significantly related to VM in GBC patients. In this study, we further evaluated whether expression of MMP-2 and MT1-MMP correlates with VM formation of GBC-SD 3-D matrices in vitro and xenografts in vivo, and if NCTD enhances TIMP-2 anti-VM activity through affecting expression of these molecules. As shown in Figs. 7-9, expression of MMP-2 and MT1-MMP proteins/mRNAs (SABC,

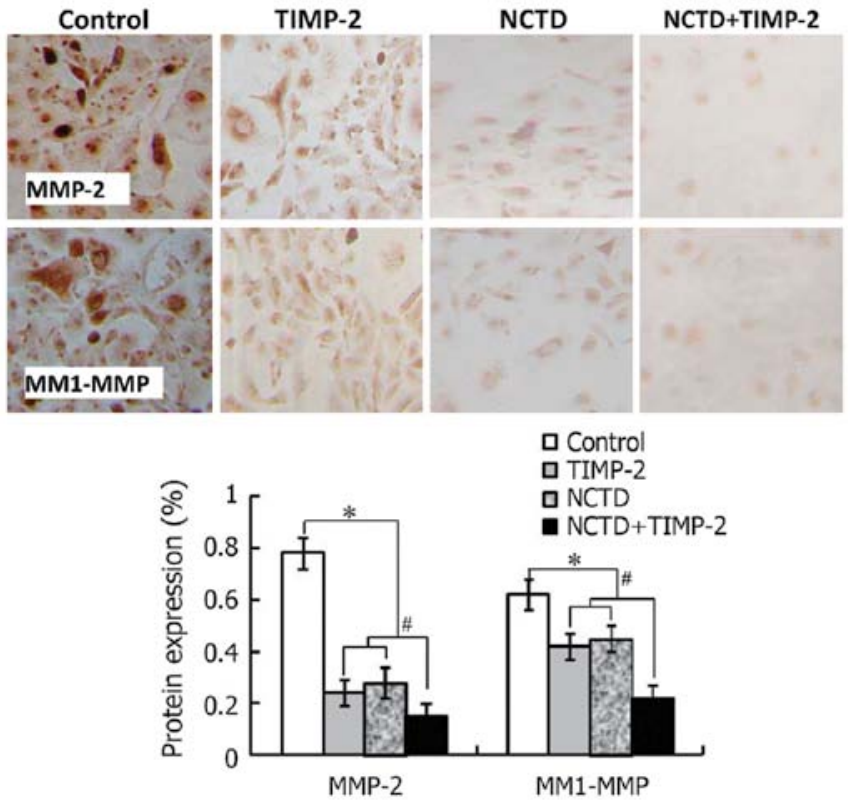

Figure 7. Expression of matrix metalloproteinase (MMP)-2 and membrane type 1-MMP (MT1-MMP) proteins from sections of three-dimensional (3-D) cultures of GBC-SD cells in vitro [streptavidin-biotin complex method (SABC), original magnification, $\mathrm{x} 200]$. The positive expression site of MMP-2 and MT1-MMP proteins presented yellow-brown reactant in cytoplasts. Overexpression of MMP-2 and MT1-MMP proteins in control group was observed. Expression of MMP-2 and MT1-MMP proteins was significantly downregulated in TIMP, norcantharidin (NCTD) or NCTD+TIMP-2 group as compared to control group (all ${ }^{*} \mathrm{P}<0.0001$ ), but was much less in NCTD+TIMP-2 group than those of TIMP or NCTD group $\left({ }^{*} \mathrm{P}<0.01\right)$.

immunofluorescence, western blotting or RT-PCR) from sections of GBC-SD 3-D cultures in vitro and/or the xenografts in vivo in control group were all upregulated. However, expression of these proteins/mRNAs in TIMP-2, NCTD or NCTD+TIMP-2 group were significantly downregulated as compared to control group (all $\mathrm{P}<0.001$ ); expression of these proteins/mRNAs was much less in NCTD+TIMP-2 group than those of TIMP or NCTD group $(\mathrm{P}<0.01)$, whereas no difference in expression of these molecules was observed between NCTD group and TIMP-2 group. Thus, these in vitro and in vivo results indicated that expression of MMP-2 and MT1-MMP in VM formation of GBC-SD cells and xenografts was significantly increased; and that NCTD enhanced TIMP-2 anti-VM activity in GBC-SD cells and xenografts through downregulating expression of MMP-2 and MT1-MMP.

\section{Discussion}

$\mathrm{VM}$ is a newly defined tumor microcirculation pattern in some highly aggressive malignant tumors which differs from endothelium-dependent angiogenesis and describes the unique ability of highly aggressive tumor cells to express endothelial cell-associated genes, and forms ECM-rich, patterned tubular networks, and is related to the poor prognosis of patients $(6,7)$. We recently reported that VM existed in human GBCs, the 3-D matrices and the xenografts of highly aggressive GBC-SD cells, correlating with the poor prognosis; and the formation of VM in GBCs through the activation of the PI3-K/MMPs/Ln-5 $\gamma 2$ or/and the EphA2/FAK/Paxillin signaling pathways in vitro 

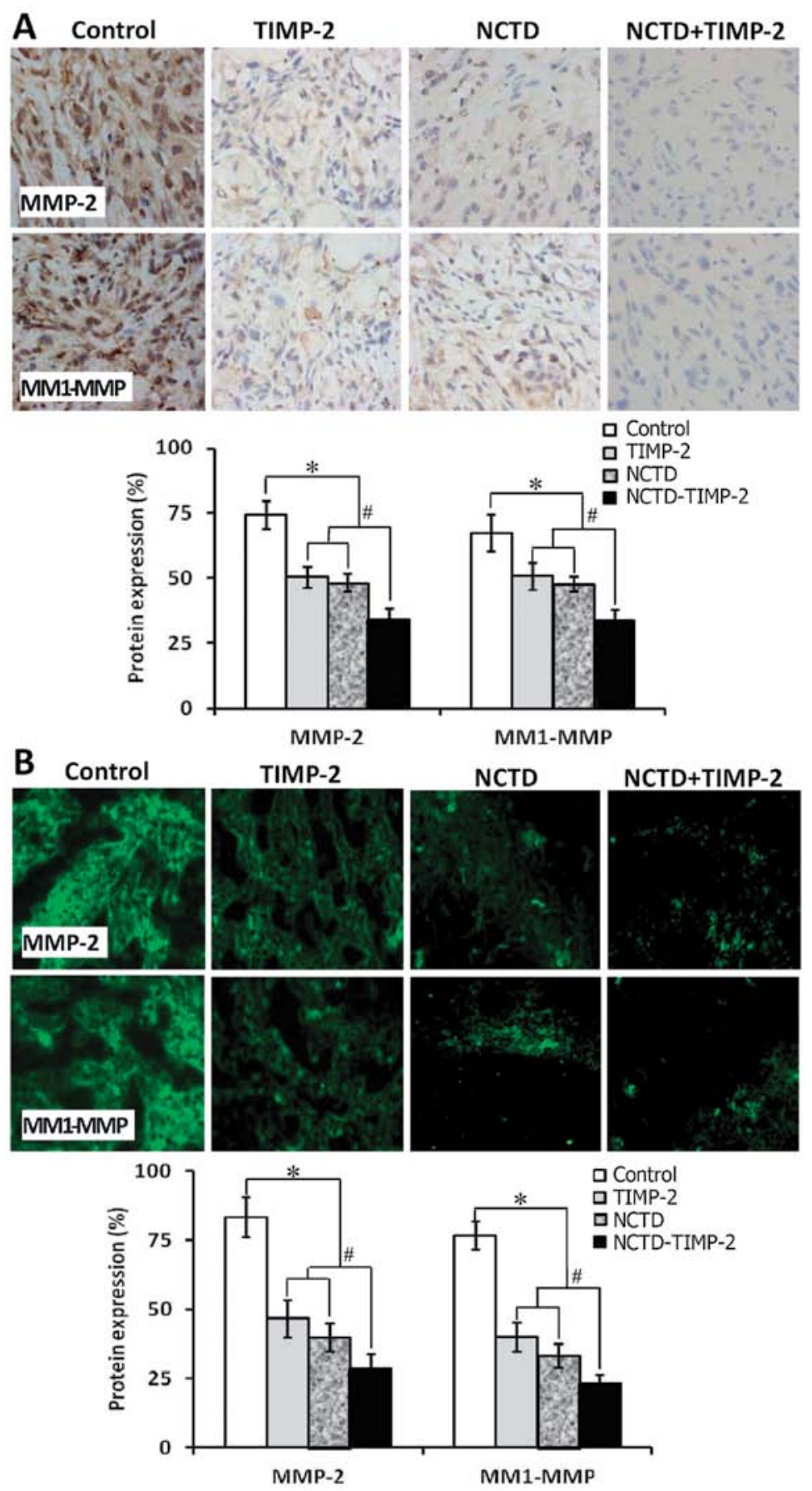

Figure 8. Expression of matrix metalloproteinase (MMP)-2 and membrane type 1-MMP (MT1-MMP) protein products from sections of GBC-SD xenografts in vivo. (A) Streptavidin-biotin complex method (SABC) (original magnification, x200). (B) Indirect immune-fluorescence method (original magnification, $\mathrm{x} 400$ ): The positive expression site of these proteins presenting bright yellow-green fluorescent staining reactant was in the cytoplasts. Expression of MMP-2 and MT1-MMP protein products were all upregulated markedly in the control group; however, expression of these protein products in tissue inhibitor of matrix metalloproteinase-2 (TIMP-2), norcantharidin (NCTD) or NCTD+TIMP-2 group was significantly downregulated as compared to control group (all ${ }^{*} \mathrm{P}<0.001$ ), and was much less in NCTD+TIMP-2 group than that of TIMP or NCTD group ( $\mathrm{P}<0.01$ ), while not different between NCTD group and TIMP-2 group.

and in vivo (25-28). In this study, we further investigated that expression of MMP-2 and MT1-MMP among human GBC specimens, GBC-SD 3-D matrices and nude mouse xenografts were related to VM in GBCs. The clinical results showed that expression of MMP-2, MT1-MMP in VM-positive GBCs was significantly higher than those in VM-negative GBCs (Fig. 1); a positive correlation between MMP-2 $(\mathrm{r}=0.374, \mathrm{P}=0.0003)$ or MT1-MMP ( $\mathrm{r}=0.449, \mathrm{P}=0.0001)$ expression and $\mathrm{VM}$ in human GBCs, a shorter survival time of VM-positive GBC patients than that of VM-negative GBC patients, and a worse survival of VM-positive GBC patients with high expression of MMP-2 or MT1-MMP than that of the patients with low expression were, respectively, observed (Fig. 1). Furthermore, the in vitro and in vivo results indicated overexpression of MMP-2 and MT1-MMP at protein and mRNA levels from sections with VM formation of GBC-SD 3-D cultures in vitro 
A
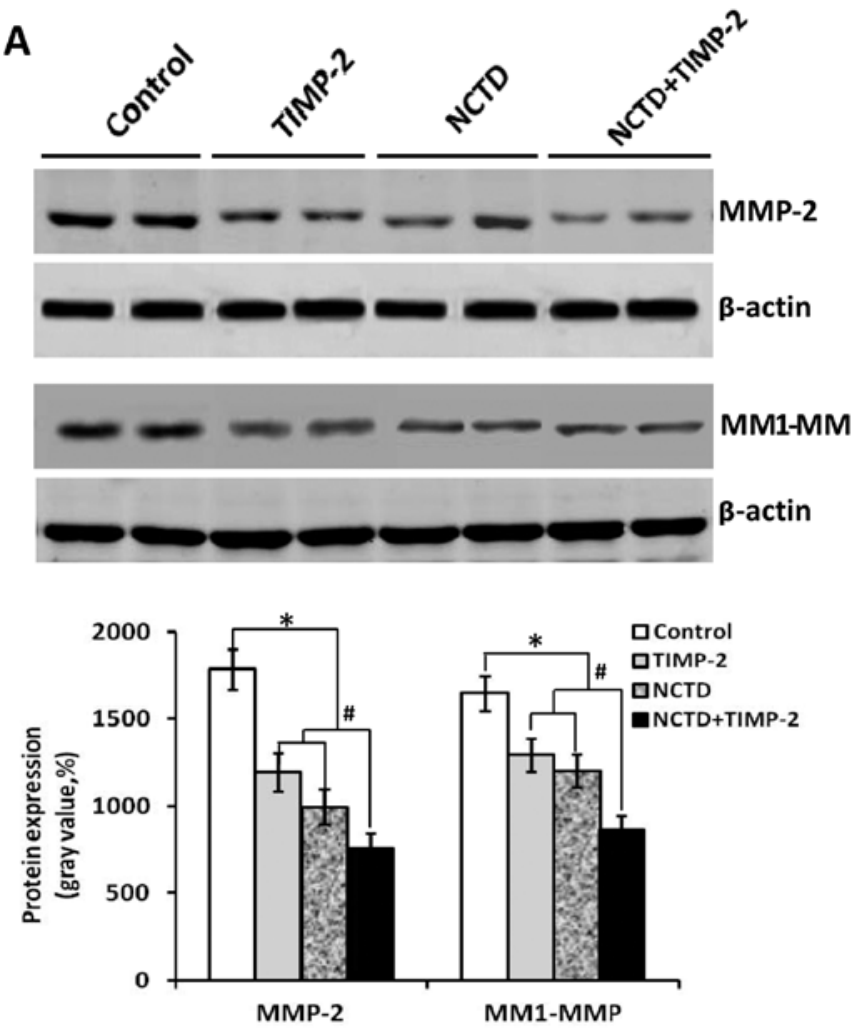

B

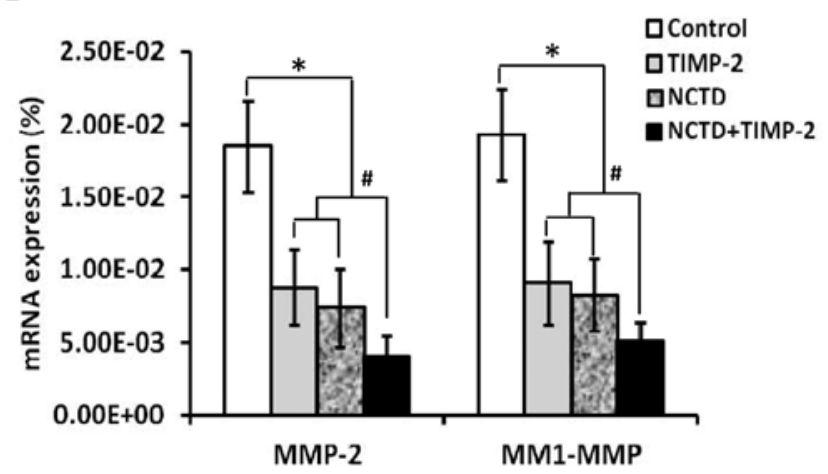

Figure 9. Expression of matrix metalloproteinase (MMP)-2 and MM1-MMP proteins/mRNAs of GBC-SD xenografts in vivo. (A) Western blotting. (B) Reverse transcription-polymerase chain reaction (RT-PCR). Expression of MMP-2 and MM1-MMP proteins/mRNAs of GBC-SD xenografts in control group was significantly upregulated. The expression of these proteins/mRNAs in tissue inhibitor of matrix metalloproteinase-2 (TIMP-2), norcantharidin (NCTD) or NCTD+TIMP-2 group was markedly downregulated as compared to control group (all " $\mathrm{P}<0.001$ ); expression of MMP-2 and MM1-MMP proteins/mRNAs of GBC-SD xenografts in NCTD+TIMP-2 group was much less than that of TIMP-2 or NCTD group $\left({ }^{\#} \mathrm{P}<0.01\right)$, whereas not different between NCTD group and TIMP-2 group.

and GBC-SD xenografts in vivo (Figs. 7-9). Thus, expression of MMP-2 and MT1-MMP was considered to significantly relate to VM in human GBCs.

Worse treatment results, poor prognosis and high aggressiveness in patients with GBCs, have been reported in sole application of adjuvant therapies for the disease, in particular, when in antitumor treatment for highly aggressive tumors with VM (15-17). It is thus necessary to develop more effective comprehensive therapies such as combining anti-VM or anti-angiogenic drugs with conventional chemotherapies, or traditional Chinese medicines which have multifunctional antitumor activities. TIMP-2 is considered to have the anti-VM activity for VM in some highly aggressive malignant tumors (23), and to prevent the formation of vasculogenic-like patterned networks (24). We reported that recombinant TIMP-2 inhibited VM formation in GBCs when added to the 3-D matrices of GBC-SD cells and injecting into GBC-SD xenografts (28). NCTD is a demethylated, low-cytotoxic derivative of cantharidin with antitumor properties, which is an active ingredient of the traditional Chinese medicine Mylabris, also a small-molecule compound synthesized from furan and maleic anhydride via the Diels-Alder reaction (29-31). It has been reported that NCTD inhibits the proliferation and growth of various human tumor cells and is clinically used to treat hepatic, gastric, colorectal and ovarian cancers (32-34). We have reported that NCTD has multiple antitumor activities for GBCs in vitro and in vivo (10,35-38). In this study, we investigated whether NCTD enhanced TIMP-2 antitumor and anti-VM activities for GBC-SD cells and xenografts. The in vivo results showed that the xenograft volume was markedly decreased, tumor inhibition was significantly increased in TIMP-2, NCTD or NCTD+TIMP-2 group as compased to control group (Fig. 2, all $\mathrm{P}<0.001$ ); these changes of the xenograft volume and the tumor inhibition were more obvious in NCTD+TIMP-2 group than those in NCTD or TIMP-2 group (Fig. 2, all $\mathrm{P}<0.01$ ); the survival time of the xenograft mice in NCTD, TIMP-2 or NCTD+TIMP-2 group was greatly prolonged as compared to control group (Fig. 2, log-rank test, $\mathrm{P}=0.0115$ ), whilst without difference on survival time among TIMP-2, NCTD and NCTD+TIMP-2 groups. In addition, VM-like channels in the xenografts in vivo and the forming and formed VM-like networks from GBC-SD 3-D matrices in vitro were significantly inhibited in TIMP-2, NCTD or NCTD+TIMP-2 group, with destroyed cellular organelles, vacuolar degeneration, cell necrosis, nuclear pyknosis, fragmentation and apoptotic bodies; and these microscopical phenomena are more obvious in NCTD+TIMP-2 group than TIMP-2 or NCTD group (Figs. 2 and 4). It was demonstrated that NCTD+TIMP-2 more effectively inhibited VM formation, tumor growth of the xenografts in vivo and the forming, and formed VM from the 3-D cultures of GBC-SD cells in vitro than NCTD or TIMP-2. Thus, we concuded that NCTD enhanced TIMP-2 antitumor and anti-VM activities for GBC-SD cells in vitro and the xenografts in vivo.

To confirm that NCTD enhances TIMP-2 anti-VM activity, we further observed the effects of NCTD+TIMP-2 on VM hemodynamics in the xenografts in vivo and the malignant phenotypes of GBC-SD cells such as proliferation, apoptosis, invasion and migration in vitro. The results showed that the xenograft center in TIMP, NCTD or NCTD+TIMP-2 group exhibited a low intensity MRI signal or a lack of signal intensity change as compared to control group (Fig. 3), a result consistent with central ischemic necrosis, disappearance of nuclei and apoptosis; and these MRI signals were much less in NCTD+TIMP-2 group than TIMP-2 or NCTD group $(\mathrm{P}<0.001)$. A significant inhibition of GBC-SD cell proliferation in a time-dependent manner was observed in TIMP-2, NCTD or NCTD+TIMP-2 group as compared to control groups (Fig. 5, all $\mathrm{P}<0.001$ ). These observations were confirmed by significantly increased cell apoptosis (Fig. 5, $\mathrm{P}<0.001)$ and microstructure changes such as microvillus 
decrease, cytoplast vacuoles, nuclear shrinkage, chromatin aggregation and typical apoptotic bodies (Fig. 4). In addition, a much smaller number of invaded and a significantly decrease gel CI of GBC-SD cells in TIMP-2, NCTD or NCTD+TIMP-2 group were also observed as compased to control group (Fig. 6 , all $\mathrm{P}<0.001)$; interesting, GBC-SD cell malignant phenotypes such as proliferation, apoptosis, invasion and migration were significantly influenced in NCTD+TIMP-2 group as compared to TIMP-2 or NCTD group (Figs. 5 and 6, $\mathrm{P}<0.01$ ). These in vivo and in vitro results indicated that NCTD enhanced TIMP-2 antitumor and anti-VM activities for GBCs through affecting VM hemodynamics and inducing xenograft ischemic necrosis in vivo, and interfering with these malignant phenotypes in GBC-SD cells in vitro.

Molecular events underlying VM displayed by highly aggressive GBCs and molecular mechanisms responsible for the NCTD antitumor are not thoroughly elucidated. Therefore, understanding the key molecular mechanisms that regulate VM in human GBCs and the exact mechanism of NCTD antitumor are important events and provide potential targets for new therapies of GBCs. In view of the importance of several key molecules or signaling pathways such as PI3-K, MMPs, Ln-5 $\gamma 2$, ECK2/EphA2 and FAK in promoting VM formation in aggressive malignant tumors (46) and $\mathrm{VM}$ formation in GBCs through the activation of the EphA2/FAK/Paxillin and the PI3-K/MMPs/Ln-5 $\gamma 2$ signaling pathways (28), we recently studied the effects of NCTD on tumor growth and VM in highly aggressive GBCs and its underlying mechanisms; the results have shown that NCTD inhibited tumor growth and VM in highly aggressive GBCs via blocking the PI3-K/MMPs/Ln-5 $\gamma 2$ or/and EphA2/FAK/Paxillin signaling pathways $(37,38)$. Because expression of MMP-2 and MT1-MMP were significantly related to VM in GBCs, we further observed in this study that NCTD enhanced TIMP-2 anti-VM activity through affecting the expression of these molecules. The in vitro and in vivo results showed that expression of MMP-2 and MT1-MMP proteins/mRNAs from sections of GBC-SD xenografts and GBC-SD cells in TIMP-2, NCTD or NCTD+TIMP-2 group was significantly downregulated as compared to control group (all $\mathrm{P}<0.001$ ); expression of these proteins/mRNAs was much less in NCTD+TIMP-2 group than those of TIMP or NCTD group $(\mathrm{P}<0.01)$, whereas no difference was seen between NCTD group and TIMP-2 group. Thus, NCTD enhanced TIMP-2 anti-VM activity for GBC-SD cells and xenografts through downregulating expression of MMP-2 and MT1-MMP.

PI3-K/MMPs/Ln-5 $\gamma 2$ and EphA2/FAK/Paxillin signaling pathways represent the predominant targets for anti-VM of tumors and cancer therapy. MMP-2 and MT1-MMP are key molecules and important mediators in the PI3-K/MMPs/Ln-5 $\gamma 2$ and the EphA2/FAK/Paxillin which regulated VM formation of aggressive malignant tumor cells $(28,37,38)$. As an important adjustor of directly affecting the cooperative interactions of MT1-MMP and MMP-2 activity, PI3-K regulates MT1-MMP and MMP-2 activity, promotes the conversion of pro-MMP into its active conformation through an interaction with TIMP-2; both enzymatically active MT1-MMP and MMP-2 therefore promote the cleavage of Ln-5 22 chain into pro-migratory $\gamma 2$ and $\gamma 2 \mathrm{x}$ fragments, then the deposition of these fragments into tumor extracellular milieu may result in increased migration, invasion and VM formation $(24,47)$. EphA2, as an upstream molecule regulating VM formation, not only activates FAK but also converges to activate the PI3-K (as effector of EphA2 downstream) leading to the activation of MMP-2, and consequent cleavage of Ln-5 $22(48,49)$; and FAK signals through Erk1/2 which regulates MMP-2 and MT1-MMP activity, thus promoting melanoma invasion and VM $(28,50)$. Thus, we deduced that NCTD enhanced TIMP-2 anti-VM activity for GBC-SD cells and xenografts through downregulating MMP-2 and MT1-MMP probably via two separate molecular mechanisms. On one hand, reduction of MT1-MMP and MMP-2 activity inhibited the PI3-K/MMPs/Ln-5 $\gamma 2$, blocked the cleavage of Ln-5 $\gamma 2$, resulting in decreased levels of the $\gamma 2$ and $\gamma 2 x$ pro-migratory fragments, and impairment of VM formation. On the other hand, downregulation of MMP-2 and MT1-MMP through inhibition of EphA2/FAK/Paxillin did not merely converge to activate PI3-K leading to the activation of MMP-2 and hindered cleavage of Ln-5 $\gamma 2$, but also blocked Erk1/2 from regulating MMP-2 and MT1-MMP activity, thus inhibiting tumor invasion and VM. These may be the molecular mechanisms responsible for NCTD, as a potential anti-VM agent or synergist, enhancing TIMP-2 anti-VM activity for human GBCs.

Collectively, overexpression of MMP-2 and MT1-MMP was significantly related to VM in human GBCs; downregulation of MMP-2 and MT1-MMP may be the underlying molecular mechanisms in NCTD enhancing TIMP-2 antitumor and anti-VM activities for human GBCs.

\section{Acknowledgements}

This study was supported by grants from the National Natural Science Foundation of China (30672073, 81372614).

\section{References}

1. Lazcano-Ponce EC, Miquel JF, Muñoz N, et al: Epidemiology and molecular pathology of gallbladder cancer. CA Cancer J Clin 51: 349-364, 2001.

2. Reddy SK and Clary BM: Surgical management of gallbladder cancer. Surg Oncol Clin N Am 18: 307-324, 2009.

3. Chakravarty KD, Yeh CN, Jan YY and Chen MF: Factors influencing long-term survival in patients with T3 gallbladder adenocarcinoma. Digestion 79: 151-157, 2009.

4. Ishii H, Furuse J, Yonemoto N, et al: Chemotherapy in the treatment of advanced gallbladder cancer. Oncology 66: 138-142, 2004.

5. Mahantshetty UM, Palled SR, Engineer R, et al: Adjuvant radiation therapy in gallbladder cancers: 10 years experience at Tata Memorial Hospital. J Cancer Res Ther 2: 52-56, 2006.

6. Maniotis AJ, Folberg R, Hess A, et al: Vascular channel formation by human melanoma cells in vivo and in vitro: vasculogenic mimicry. Am J Pathol 155: 739-752, 1999.

7. Warso MA, Maniotis AJ, Chen X, et al: Prognostic significance of periodic acid-Schiff-positive patterns in primary cutaneous melanoma. Clin Cancer Res 7: 473-477, 2001.

8. Tian $\mathrm{F}$, Zhang $\mathrm{X}$, Tong $\mathrm{Y}$, et al: $\mathrm{PE}$, a new sulfated saponin from sea cucumber, exhibits anti-angiogenic and anti-tumor activities in vitro and in vivo. Cancer Biol Ther 4: 874-882, 2005.

9. Zhou YX and Huang YL: Antiangiogenic effect of celastrol on the growth of human glioma: an in vitro and in vivo study. Chin Med J (Engl) 122: 1666-1673, 2009.

10. Zhang JT, Fan YZ, Chen CQ, Zhao ZM and Sun W: Norcantharidin: A potential antiangiogenic agent for gallbladder cancers in vitro and in vivo. Int J Oncol 40: 1501-1514, 2012. 
11. Zhang S, Li M, Gu Y, et al: Thalidomide influences growth and vasculogenic mimicry channel formation in melanoma. $\mathrm{J}$ Exp Clin Cancer Res 27: 60, 2008.

12. Cong R, Sun Q, Yang L, et al: Effect of Genistein on vasculogenic mimicry formation by human uveal melanoma cells. J Exp Clin Cancer Res 28: 124, 2009.

13. Fu D, He X, Yang S, et al: Zoledronic acid inhibits vasculogenic mimicry in murine osteosarcoma cell line in vitro. BMC Musculoskelet Disord 12: 146, 2011.

14. Chen LX, He YJ, Zhao SZ, et al: Inhibition of tumor growth and vasculogenic mimicry by curcumin through downregulation of the EphA2/PI3K/MMP pathway in a murine choroidal melanoma model. Cancer Biol Ther 11: 229-235, 2011.

15. Chen HX and Cleck JN: Adverse effects of anticancer agents that target the VEGF pathway. Nat Rev Clin Oncol 6: 465-477, 2009.

16. Higa GM and Abraham J: Biological mechanisms of bevacizumab-associated adverse events. Expert Rev Anticancer Ther 9: 999-1007, 2009.

17. van der Schaft DW, Seftor RE, Seftor EA, et al: Effects of angiogenesis inhibitors on vascular network formation by human endothelial and melanoma cells. J Natl Cancer Inst 96 : 1473-1477, 2004

18. McCawley LJ and Matrisian LM: Matrix metalloproteinases: multifunctional contributors to tumor progression. Mol Med Today 6: 149-156, 2000.

19. Stetler-Stevenson WG: Matrix metalloproteinases in angiogenesis: a moving target for therapeutic intervention. J Clin Invest 103: 1237-1241, 1999.

20. Sood AK, Fletcher MS, Coffin JE, et al: Functional role of matrix metalloproteinases in ovarian tumor cell plasticity. Am J Obstet Gynecol 190: 899-909, 2004

21. Hess AR, Seftor EA, Seftor RE and Hendrix MJ: Phosphoinositide 3-kinase regulates membrane type 1-matrix metalloproteinase (MMP) and MMP-2 activity during melanoma cell vasculogenic mimicry. Cancer Res 63: 4757-4762, 2003.

22. Hendrix MJ, Seftor EA, Kirschmann DA, Quaranta V and Seftor RE: Remodeling of the microenvironment by aggressive melanoma tumor cells. Ann N Y Acad Sci 995: 151-161, 2003.

23. Albini A, Melchiori A, Santi L, et al: Tumor cell invasion inhibited by TIMP-2. J Natl Cancer Inst 83: 775-779, 1991.

24. Seftor RE, Seftor EA, Koshikawa N, et al: Cooperative interactions of laminin 5 gamma 2 chain, matrix metalloproteinase- 2 , and membrane type-1-matrix/metalloproteinase are required for mimicry of embryonic vasculogenesis by aggressive melanoma. Cancer Res 61: 6322-6327, 2001

25. Fan YZ, Sun W, Zhang WZ and Ge CY: Vasculogenic mimicry in human primary gallbladder carcinoma and clinical significance thereof. Zhonghua Yi Xue Za Zhi 87: 145-149, 2007 (In Chinese).

26. Sun W, Shen ZY, Zhang H, Fan YZ, Zhang WZ, Zhang JT, $\mathrm{Lu} X \mathrm{XS}$ and Ye C: Overexpression of HIF-1 $\alpha$ in primary gallbladder carcinoma and its relation to vasculogenic mimicry and unfavourable prognosis. Oncol Rep 27: 1990-2002, 2012.

27. Sun W, Fan YZ, Zhang WZ and Ge CY: A pilot histomorphology and hemodynamic of vasculogenic mimicry in gallbladder carcinomas in vivo and in vitro. J Exp Clin Cancer Res 30: 46, 2011.

28. Lu XS, Sun W, Ge CY, Zhang WZ and Fan YZ: Contribution of the PI3-K/MMPs/Ln-5 $\gamma 2$ and EphA2/FAK/Paxillin signaling pathways to tumor growth and vasculogenic mimicry of gallbladder carcinomas. Int J Oncol 42: 2103-2115, 2013.

29. Wang GS: Medical uses of mylabris in ancient China and recent studies. J Ethnopharmacol 26: 147-162, 1989.

30. Liu J, Gao J and Liu X: Advances in the study of Cantharidin and its derivatives. Zhong Yao Cai 26: 453-455, 2003.

31. Ho YP, To KK, Au-Yeung SC, et al: Potential new antitumor agents from an innovative combination of demethylcantharidin, a modified traditional Chinese medicine, with a platinum moiety. J Med Chem 44: 2065-2068, 2001.
32. Yang EB, Tang WY, Zhang K, Cheng LY and Mack PO: Norcantharidin inhibits growth of human HepG2 cell-transplanted tumor in nude mice and prolongs host survival. Cancer Lett 117: 93-98, 1997.

33. Yi SN, Wass J, Vincent $P$ and Iland $H$ : Inhibitory effect of norcantharidin on K562 human myeloid leukemia cells in vitro. Leuk Res 15: 883-886, 1991.

34. An WW, Wang MW, Tashiro S, Onodera S and Ikejima T: Norcantharidin induces human melanoma A375-S2 cell apoptosis through mitochondrial and caspase pathways. J Korean Med Sci 19: 560-566, 2004.

35. Fan YZ, Fu JY, Zhao ZM and Chen CQ: Inhibitory effect of norcantharidin on the growth of human gallbladder carcinoma GBC-SD cells in vitro. Hepatobiliary Pancreat Dis Int 6: 72-80, 2007.

36. Fan YZ, Zhao ZM, Fu JY, Chen CQ and Sun W: Norcantharidin inhibits growth of human gallbladder carcinoma xenografted tumors in nude mice by inducing apoptosis and blocking the cell cycle in vivo. Hepatobiliary Pancreat Dis Int 9: 414-422, 2010.

37. Zhang JT, Sun W, Zhang WZ, Ge CY, Liu ZY, Zhao ZM, Lu XS and Fan YZ: Norcantharidin inhibits tumor growth and vasculogenic mimicry of human gallbladder carcinomas by suppression of the PI3-K/MMPs/Ln-5 $\gamma 2$ signaling pathway. BMC Cancer 14: 193, 2014.

38. Wang H, Sun W, Zhang WZ, Ge CY, Zhang JT, Liu ZY and Fan YZ: Inhibition of tumor vasculogenic mimicry and prolongation of host survival in highly aggressive gallbladder cancers by norcantharidin via blocking the ephrin type a receptor $2 /$ focal adhesion kinase/Paxillin signaling pathway. PLoS One 9: e96982, 2014

39. McNamara MG, Metran-Nascente C and Knox JJ: State-of-the-art in the management of locally advanced and metastatic gallbladder cancer. Curr Opin Oncol 25: 425-431, 2013.

40. Li M, Gu Y, Zhang Z, et al: Vasculogenic mimicry: a new prognostic sign of gastric adenocarcinoma. Pathol Oncol Res 16: 259-266, 2010.

41. Wang CJ, Zhou ZG, Holmqvist A, et al: Survivin expression quantified by Image Pro-Plus compared with visual assessment. Appl Immuohistochem Mol Morphol 17: 530-535, 2009.

42. Xavier LL, Viola GG, Ferraz AC, et al: A simple and fast densitometric method for the analysis of tyrosine hydroxylase immunoreactivity in the substantia nigra pars compacta and in the ventral tegmental area. Brain Res Protoc 16: 58-64, 2005.

43. Situ DR, Hu Y, Zhu ZH, et al: Prognostic relevance of $\beta$-catenin expression in T2-3N0M0 esophageal squamous cell carcinoma. World J Gastroenterol 16: 5195-5202, 2010.

44. Zlobec I, Steele R, Terracciano L, Jass JR and Lugli A: Selecting immunohistochemical cut-off scores for novel biomarkers of progression and survival in colorectal cancer. J Clin Pathol 60: 1112-1116, 2007.

45. Kilkenny C, Browne WJ, Cuthill IC, Emerson M and Altman DG: Improving bioscience research reporting: the ARRIVE guidelines for reporting animal research. PLoS Biol 8: e1000412, 2010.

46. Fan YZ and Sun W: Molecular regulation of vasculogenic mimicry in tumors and potential tumor-target therapy. World $\mathbf{J}$ Gastrointest Surg 2: 117-127, 2010.

47. Seftor RE, Seftor EA, Kirschmann DA and Hendrix MJ: Targeting the tumor microenvironment with chemically modified tetracyclines: inhibition of laminin 5 gamma2 chain promigratory fragments and vasculogenic mimicry. Mol Cancer Ther 1: 1173-1179, 2002.

48. Hess AR, Seftor EA, Gardner LM, et al: Molecular regulation of tumor cell vasculogenic mimicry by tyrosine phosphorylation: role of epithelial cell kinase (Eck/EphA2). Cancer Res 61: 3250-3255, 2001.

49. Margaryan NV, Strizzi L, Abbott DE, et al: EphA2 as a promoter of melanoma tumorigenicity. Cancer Biol Ther 8: 279-288, 2009.

50. Hess AR and Hendrix MJ: Focal adhesion kinase signaling and the aggressive melanoma phenotype. Cell Cycle 5: 478-480, 2006. 